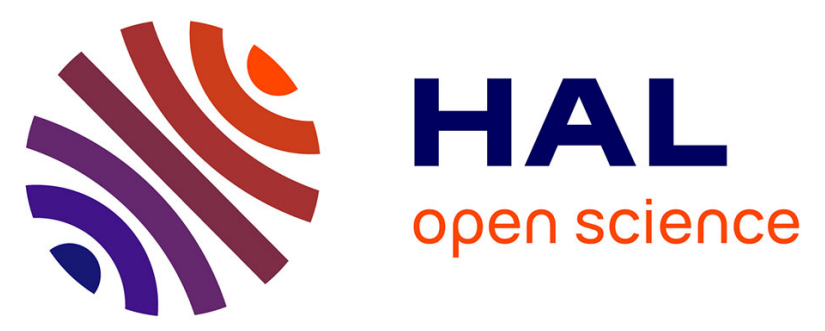

\title{
Year-to-year variability of the phytoplankton bloom in the southern Adriatic Sea (1998-2000): Sea-viewing Wide Field-of-view Sensor observations and modeling study
}

R. Santoleri, Viva Banzon, Salvatore Marullo, Ernesto Napolitano, Fabrizio d'Ortenzio, Robert W Evans

\section{To cite this version:}

R. Santoleri, Viva Banzon, Salvatore Marullo, Ernesto Napolitano, Fabrizio d'Ortenzio, et al.. Yearto-year variability of the phytoplankton bloom in the southern Adriatic Sea (1998-2000): Sea-viewing Wide Field-of-view Sensor observations and modeling study. Journal of Geophysical Research, 2003, 108 (C9), 10.1029/2002JC001636 . hal-03137142

\author{
HAL Id: hal-03137142 \\ https://hal.science/hal-03137142
}

Submitted on 11 Feb 2021

HAL is a multi-disciplinary open access archive for the deposit and dissemination of scientific research documents, whether they are published or not. The documents may come from teaching and research institutions in France or abroad, or from public or private research centers.
L'archive ouverte pluridisciplinaire HAL, est destinée au dépôt et à la diffusion de documents scientifiques de niveau recherche, publiés ou non, émanant des établissements d'enseignement et de recherche français ou étrangers, des laboratoires publics ou privés. 


\title{
Year-to-year variability of the phytoplankton bloom in the southern Adriatic Sea (1998-2000): Sea-viewing Wide Field-of-view Sensor observations and modeling study
}

\author{
R. Santoleri, ${ }^{1}$ V. Banzon, ${ }^{2}$ S. Marullo, ${ }^{3}$ E. Napolitano, ${ }^{3}$ F. D’Ortenzio, ${ }^{4}$ \\ and R. Evans 5 \\ Received 11 September 2002; revised 3 March 2003; accepted 18 April 2003; published 17 September 2003.
}

[1] The year-to-year variability in the timing, duration, and spatial extent of the surface phytoplankton bloom over the winter-spring period is examined in the southern Adriatic Sea using Sea-viewing Wide Field-of-view Sensor (SeaWiFS)-derived chlorophyll images for three years (1998, 1999, and 2000). Each year's image time series shows that blooms were intermittent and differed in onset, duration, and intensity with relatively low values observed in 2000 . The relation between atmospheric forcing and interannual variability of the bloom timing and intensity is investigated using a coupled physical-biological model. The simulations focus on the effect of cumulative buoyancy loss on convective depths and its implications on surface nutrient availability, chlorophyll concentrations, and other ecosystem components during the study period. We test the hypothesis that the south Adriatic bloom is essentially controlled by the local winter climatic conditions (i.e., maximum convective depth), as suggested by recent findings, rather than the available nutrient pool at the intermediate depths $(200-800 \mathrm{~m})$, which also varies from year to year. For all three years the simulations produced convective depths that were in good agreement with in situ observations. However, the fluctuations in SeaWiFS phytoplankton biomass could be reproduced only if the particular year's nutrient pool was also taken into account. Thus the most probable explanation for the low SeaWiFS phytoplankton biomass observed in 2000 is the reduced nutrient pool because of the return from the transient phase to the pretransient regime of the Mediterranean Sea. Our results indicate that the south Adriatic bloom is a complex phenomenon and cannot simply be explained by interannual changes in convective depth. INDEX TERMS: 4855 Oceanography: Biological and Chemical: Plankton; 4842 Oceanography: Biological and Chemical: Modeling; 4520 Oceanography: Physical: Eddies and mesoscale processes; 4215 Oceanography: General: Climate and interannual variability (3309); 4275 Oceanography: General: Remote sensing and electromagnetic processes (0689); KEYWORDS: SeaWiFS, chlorophyll, spring bloom, ecosystem, deep convection, Adriatic

Citation: Santoleri, R., V. Banzon, S. Marullo, E. Napolitano, F. D’Ortenzio, and R. Evans, Year-to-year variability of the phytoplankton bloom in the southern Adriatic Sea (1998-2000): Sea-viewing Wide Field-of-view Sensor observations and modeling study, J. Geophys. Res., 108(C9), 8122, doi:10.1029/2002JC001636, 2003.

\section{Introduction}

[2] Open ocean deep convection is associated with deep and intermediate water formation. Deep mixing can extend down several hundreds up to thousand meters, which is much greater compared to the seasonal winter overturn. Interannual variability in the extent of deepwater formation

\footnotetext{
${ }^{1}$ Istituto delle Scienze dell'Atmosfera e del Clima (Sezione di Roma), Consiglio Nazionale delle Ricerche, Rome, Italy.

${ }^{2}$ Department of Physics, University of Miami, Miami, Florida, USA.

${ }^{3}$ Ente per le Nuove tecnologie l'Energia e l'Ambiente-Centro Ricerche Casaccia, Rome, Italy.

${ }^{4}$ Stazione Zoologica A. Dohrn, Naples, Italy.

${ }^{5}$ Rosenstiel School of Marine and Atmospheric Sciences, University of Miami, Miami, Florida, USA.

Copyright 2003 by the American Geophysical Union. 0148-0227/03/2002JC001636\$09.00
}

is driven by meteorological conditions; thus the convective penetration depth is principally determined by the year-toyear variability in local heat fluxes [e.g., Mertens and Schott, 1998; Visbeck et al., 1995; Lascaratos et al., 1993]. The extraction of the buoyancy occurs over the preconditioning phase (which extends from autumn to the violent mixing event in winter) and determines the maximum penetration depth and the T-S properties of the newly formed dense water. The physical process of deep convection is reviewed in detail by Marshall and Schott [1999]. The deep overturning process also brings up an additional supply of nutrients and "seed" phytoplankton complementary to that furnished by seasonal convection, thus modulating the spring bloom. Within the mixed convective patch, the water mass sinking down to thousands of meters is compensated by a weaker upward motion that brings up to the surface algal spores and cells that have sunk to the deep 
pycnocline [Backhaus et al.,1999]. Thus year-to-year variations in springtime nutrient availability and chlorophyll concentrations may be explained to a large extent by variations in meteorological forcing through its effect on convective penetration depth. However, vertical mixing can also retard productivity because of the transport of phytoplankton below Svedrup's critical depth [Dutkiewicz et al., 2001; Follows and Dutkiewicz, 2002].

[3] Even after the deep convection phase, development of the spring bloom continues to be affected by physical processes. Lévy et al. [1999] use an eddy-resolving primitive equation model driven by a constant atmospheric forcing to show that mesoscale features associated with water column restratification interact with the spring bloom, thereby determining the spatial pattern of primary production and of chlorophyll concentrations. In a subsequent work, Lévy et al. [2000] perform numerical experiments to isolate the effects of wind from that of progressive seasonal warming on phytoplankton distributions. On a basin and seasonal scale, their results reaffirm the classical scenario that the onset of spring bloom results from thermal restratification induced by the progressive increase of solar radiation, while shorter-term bloom fluctuations are explained by the high-frequency variability in the meteorological forcing that acts principally on the dynamical restratification driven by Ekman transport and other mesoscale processes.

[4] In the predominantly oligotrophic Mediterranean Sea, atmospheric forcing does not favor winter basin-wide upward mixing of nutrient-rich intermediate and deep waters. However, orographically forced local winds often reach gale force and, when combined with oceanographic preconditioning, can result in deep convection and surface nutrient enrichment. Thus, away from areas affected by river runoff in the Mediterranean, high productivity occurs mainly at sites of local deep convection [Antoine et al., 1995]. In fact, unlike the more classic North Atlantic situation, the Mediterranean spring bloom does not occur as a distinct or extended event. In the western Mediterranean basin, the spring bloom is most pronounced in the northern part [Morel and André, 1991], where the Gulf of Lion, a wellknown site of dense water formation is located [MEDOC Group, 1970; Leaman and Schott, 1991]. Away from the coastal areas, the eastern Mediterranean basin is generally characterized by low annual productivity and a weak seasonal chlorophyll signal, with local exceptions such as the Rhodes Gyre and the southern Adriatic Gyre [Antoine et al., 1995]. High pigment concentrations and enhanced nutrient availability in the surface layer have been observed in these gyres following deep convection events [e.g., Zavatarelli et al., 1998; Sur et al., 1993; Crispi et al., 1999; Civitarese and Gacic, 2001; Napolitano et al., 2000].

[5] This paper focuses only on the south Adriatic Gyre (SAG), a well known site of dense water formation [Pollak, 1951], but the methodology and results are applicable to other sites of deep convection. The SAG is small (diameter of $100 \mathrm{Km}$ ) relative to the dimensions of the Mediterranean basin and is formed by the inflow of surface and subsurface water of Ionian origin. It is topographically constrained by the Italian and Dalmatian coasts and the presence of a $1200 \mathrm{~m}$ depression which is bounded by a $250 \mathrm{~m}$ Palagruza sill to the north and an $800 \mathrm{~m}$ sill at the Otranto Straits to the

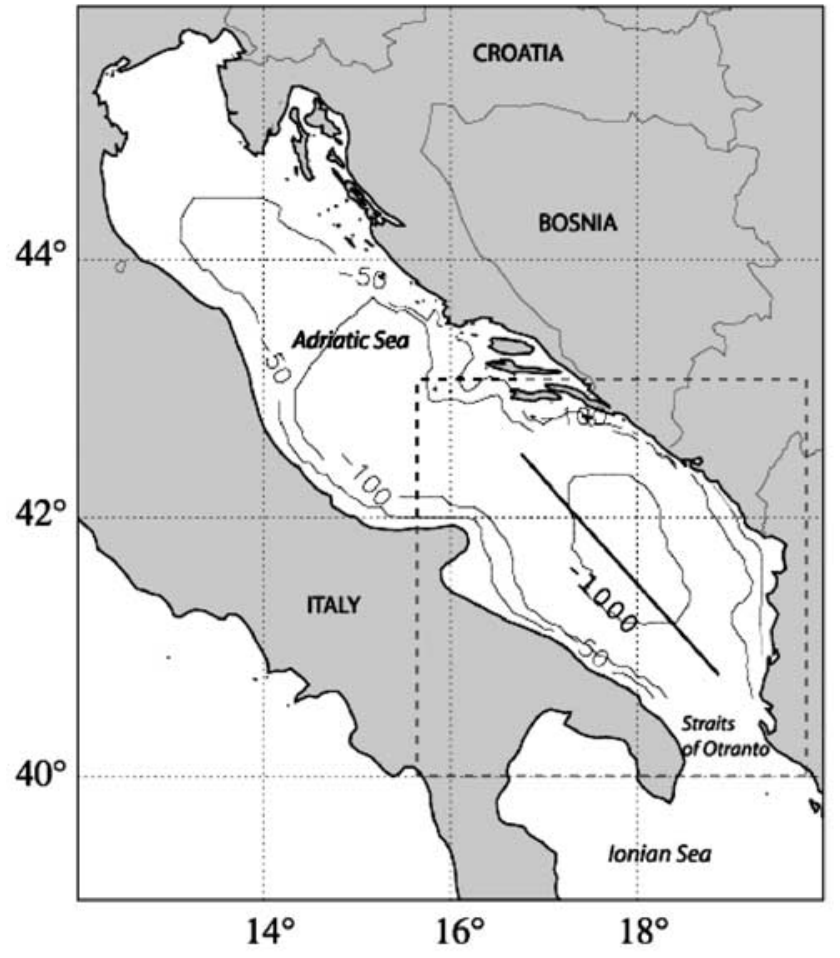

Figure 1. Bathymetric map of the Adriatic Sea. Box shows area represented in SeaWiFS images (Figures 3-6). The thick line shows the transect for extraction of chlorophyll data from individual passes for Figures 14 (top).

south (Figure 1). Dense water is formed in the SAG during winter time by excess cooling and evaporation [Artegiani et al., 1997a]. The presence of this permanent cyclonic gyre provides a main precondition for dense water formation analogous to almost all open ocean convention regimes [Killworth, 1983]. An important factor is the presence of salty Levantine Intermediate Water (LIW) at $200-800 \mathrm{~m}$. Formation occurs during strong Bora events (cold and dry wind from northeast) that persist for several days during which significant heat is lost. The diameter of the area of convection (mixed patch) is about $50 \mathrm{Km}$ and vertically extends down to the bottom $(1200 \mathrm{~m})$ [Artegiani et al., 1997a].

[6] Interannual changes in subsurface nutrient availability in the SAG and inflowing Ionian intermediate water within the last decade reported by Civitarese and Gacic [2001] has drawn great interest because it suggests that SAG biogeochemistry was not greatly affected by the East Mediterranean Transient (EMT) [see Malanotte-Rizzoli et al., 2003]. Before the last decade, deep water formed in the SAG was considered the principal source of Eastern Mediterranean Deep Water [Wüst, 1961]. During the EMT, the Adriatic Deep Water contribution was greatly reduced relative to the Aegean, with consequences on the Mediterranean deep thermohaline circulation [Roether et al., 1996]. The data of Civitarese and Gacic [2001] show an increased nutrient availability below $200 \mathrm{~m}$ from 1987 to 1995 during the EMT and a decrease after 1997 indicating a return to pretransient conditions [see also Klein et al., 2000]. Civitarese and Gacic [2001] found that this increase of 
the SAG internal nutrient pool was not effective in determining a significant increase in the new production because of the concomitant relaxation of the winter vertical convection, and conclude that the interannual variability the surface nutrients and new production in the SAG is strongly controlled by deep convection penetration depth rather than the nutrient content of the intermediate waters. This idea is further developed by Gacic et al. [2002] in their analysis of vertical carbon flux data for 1998 with remotely sensed algal biomass and in situ nutrient data.

[7] In this paper, we examine SeaWiFS imagery of south Adriatic Gyre to characterize the year-to-year variability in timing and duration of the surface spring bloom from January to April over three years (1998-2000). We tested the hypothesis that the south Adriatic bloom is controlled by local winter climatic conditions that determine the convective mixing and the amount of nutrients available to the autotrophs [Gacic et al., 2002; Civitarese and Gacic, 2001]. Thus the surface bloom progression can be explained principally by mixed layer deepening and restratification. The relation between atmospheric forcing and interannual variability of bloom timing and intensity is investigated using a one-dimensional (1-D) coupled physical-biological model discussed in the next paragraph. The model is used to demonstrate the effect of cumulative buoyancy loss on convective depths and its implications on surface nutrient availability, chlorophyll concentrations, and other ecosystem components during the study period.

[8] Satellite imagery has provided many useful insights about deep convection in the southern Adriatic Sea. Using AVHRR imagery, Gacic et al. [1997] found that the SAG temperature minimum was prominent from late autumn to early winter (corresponding to the preconditioning and deepwater formation phases) and exhibited strong interannual variability. Buongiorno-Nardelli and Salusti [2000] estimated the SAG deep convection feature's horizontal space scale in thermal images, which permitted them to compute the depth of the convective chimney from theoretical criteria. Barale et al. [1986] noted the co-occurrence of relatively high CZCS pigment levels $\left(0.6-0.7 \mathrm{mg} \mathrm{m}^{-3}\right)$ with meteorological conditions associated with dense water formation. Variability in the extent of Adriatic dense water formation has been invoked to explain differences between years (1998 and 1999) in satellite-derived monthly temperature and chlorophyll fields [Banzon et al., 1999].

[9] The use of the ecosystem model to estimate the main characteristics of deep convection and biological response is not novel. Even if deep-convection phenomena are fairly complex, the main characteristics (such as mixed layer depth, T-S properties of the new formed dense water) can be estimated with a mixed layer model forced by surface fluxes at the center of the convective area [e.g., Mertens and Schott, 1998, Visbeck et al., 1995]. Similarly, the ecological response to the deep convection has been successfully simulated with a 1-D coupled physical-biological model in the Mediterranean and was able to explain the observed seasonal cycle of nutrients and chlorophyll derived from CZCS climatology [e.g., Lévy et al., 1998; Napolitano et al., 2000]. Concerning the Adriatic Sea and particularly the SAG, to our knowledge, the only 1-D modeling study was conducted by Allen et al. [1998] with climatologic forcing functions. Here we use the one dimensional ecosystem
Table 1. Availability of SeaWiFS Imagery and Mean Cloud Coverage in the Study Area

\begin{tabular}{lcc}
\hline & Cloud Cover Percent & Number of Images Used \\
\hline January 1998 & 80.1 & 20 \\
February 1998 & 61.0 & 22 \\
March 1998 & 55.6 & 29 \\
April 1998 & 63.2 & 24 \\
January 1999 & 75.3 & 23 \\
February 1999 & 62.3 & 25 \\
March 1999 & 65.2 & 30 \\
April 1999 & 68.9 & 26 \\
January 2000 & 54.1 & 28 \\
February 2000 & 64.1 & 27 \\
March 2000 & 57.8 & 24 \\
April 2000 & 43.2 & 20 \\
Total & & 298 \\
\hline
\end{tabular}

model since it is an essential prerequisite to understand and quantify the relative roles of different physical and biological processes on the general ecosystem characteristics, in anticipation of a three-dimensional basin-wide implementation.

[10] The paper is organized as follows. Section 2 presents the data and processing. Section 3 describes the physicalbiological model and its implementation. In section 4, the SeaWiFS imagery time series is described. Then the role of atmospheric forcing on vertical water column structure and the biochemical response is examined year by year using the model results in section 5. A comparison between the SeaWiFS observations and the model results is presented in section 6. In section 7 we discuss the effect of physical and biological factors affecting the bloom events by means of modeling sensitivity experiments and theoretical analysis. Conclusions are given in section 8 .

\section{Data and Calculations}

\subsection{SeaWiFS Data}

[11] The $1 \mathrm{~km}$ resolution SeaWiFS data for the period 1 January to 30 April 1998-2000 used for this study was collected by the receiving station at the Istituto di Scienze dell'Atmosfera e del Clima (ISAC), Rome, Italy. SeaWiFS Level 2 chlorophyll $a$ maps were generated using the twoband Ocean Color algorithm version 2 (OCv2) [O'Reilly et al., 1998] implemented on SeaDAS software, and mapped to a $1 \mathrm{~km}$ resolution (University of Miami DSP software). The OCv2 is an empirical equation based on a relating remote sensing reflectances in the 490 and $555 \mathrm{~nm}$ bands to chlorophyll $a$ concentration measurements. Analysis of SeaWiFS satellite postlaunch data (distributed world wide) indicates that OCv2 performs well for case 1 waters [Maritorena and O'Reilly, 2000]. For the Mediterranean Sea, D'Ortenzio et al. [2002] found the OCv2 algorithm to be reliable for concentrations above $0.2 \mathrm{mg} \mathrm{m}^{-3}$ but tended to overestimate below $0.2 \mathrm{mg} \mathrm{m}^{-3}$.

[12] A total of 298 remapped chlorophyll images was produced for the Adriatic Sea using all the available SeaWiFS passes. Chlorophyll maps were flagged for clouds or other contamination factors using a sequence of mask criteria [McClain et al., 1995]: land, cloud, sun glint, atmospheric correction failure, high total radiance, large solar zenith angle $\left(70^{\circ}\right)$, large spacecraft zenith angle $\left(56^{\circ}\right)$, coccolithophores, negative Lw, and Lwn (555) 
$<0.15 \mathrm{Wm}^{-2} \mathrm{sr}^{-1}$. Table 1 shows the availability of the images per month and the monthly mean cloud cover in the south Adriatic area based on the SeaWiFS cloud masks.

\subsection{Surface Heat Fluxes}

[13] The net surface heat flux at the air-sea interface $\left(\mathrm{Q}_{\text {tot }}\right)$, consists of the absorbed solar radiation $\left(\mathrm{Q}_{\mathrm{s}}\right)$ minus the back radiation $\left(\mathrm{Q}_{\mathrm{b}}\right)$, latent $\left(\mathrm{Q}_{\mathrm{e}}\right)$ and sensible $\left(\mathrm{Q}_{\mathrm{h}}\right)$ heat flux:

$$
\mathrm{Q}_{\text {tot }}=\mathrm{Q}_{\mathrm{s}}-\left(\mathrm{Q}_{\mathrm{e}}+\mathrm{Q}_{\mathrm{h}}+\mathrm{Q}_{\mathrm{b}}\right)
$$

[14] Each component of the heat budget can be computed using the so-called bulk formulae that are based on knowledge of some meteorological parameters. In this work we obtained sea level atmospheric pressure, air temperature at $2 \mathrm{~m}$, dew point temperature, cloud cover, zonal and meridional wind components from European Centre for Medium-Range Weather Forecasts (ECMWF). Sea surface temperature at the same location was extracted from daily AVHRR Pathfinder data [Kilpatrick et al., 2001]. The SST data voids were interpolated in space and time using objective analysis [Marullo et al., 1999]. The low resolution of the ECMWF data $\left(0.5625^{\circ}\right)$ precludes a bidimensional analysis of the atmospheric forcing over the SAG (which is only $100 \mathrm{~km}$ in diameter). Therefore here we selected the ECMWF grid point located in the center of the gyre $\left(41.5^{\circ} \mathrm{N}, 18.0^{\circ} \mathrm{E}\right)$ which can be considered representative of the meteorological conditions of the gyre.

[15] The Reed's [1977] relation was used to estimate mean daily insolation including cloud attenuation. The shortwave radiation budget including the effect of the sea surface albedo is:

$$
\mathrm{Q}_{\mathrm{s}}=\mathrm{Q}_{0}(1-0.637 \mathrm{C}+0.0019 \mathrm{~h})(1-\mathrm{A})
$$

where $\mathrm{Q}_{0}$ is the clear sky radiation, $\mathrm{C}$ is the mean daily cloud clover, $\mathrm{h}$ is the solar elevation at noon and $\mathrm{A}$ is the sea surface albedo.

[16] The latent heat flux was computed using:

$$
\mathrm{Q}_{\mathrm{e}}=\rho_{a} \mathrm{C}_{\mathrm{e}} \mathrm{w}\left(\mathrm{q}-\mathrm{q}_{\mathrm{s}}\right) \mathrm{L}
$$

where $\rho_{\mathrm{a}}$ is the air density, $\mathrm{C}_{\mathrm{e}}=1.14 \times 10^{-3}$ is the Dalton number, $\mathrm{w}$ is the wind intensity, $\mathrm{q}$ is the specific humidity, $\mathrm{q}_{\mathrm{s}}$ is the saturation humidity and $\mathrm{L}=2.456 \times 10^{6} \mathrm{~J} \mathrm{~kg}^{-1}$ is latent heat of water [Gilman and Garrett, 1994]. The specific humidity and saturation humidity were computed from water vapor pressure and saturated water vapor pressure [Gill, 1982, pp. 40-41] that in turn were calculated from the ECMWF dew point temperature and AVHRR sea surface temperature, taking into account atmospheric pressure correction and salt correction [Gill, 1982, p. 606].

[17] The sensible heat flux was computed using:

$$
\mathrm{Q}_{\mathrm{h}}=\rho_{\mathrm{a}} \mathrm{C}_{\mathrm{p}} \mathrm{C}_{\mathrm{h}}\left(\mathrm{T}_{\mathrm{s}}-\mathrm{T}_{\mathrm{a}}\right) \mathrm{w}
$$

where $C_{p}=1005 \mathrm{~J} \mathrm{~kg}^{-1} \mathrm{~K}^{-1}$ is the specific heat of air, $T_{\mathrm{s}}$ is sea surface temperature and $\mathrm{T}_{\mathrm{a}}$ is air temperature. The Stanton number $C_{h}$ was estimated as a function of the wind intensity:

$$
\begin{aligned}
& \mathrm{C}_{\mathrm{h}}=\left\{0.720+\left[0.0175 \mathrm{w}\left(\mathrm{T}_{\mathrm{s}}-\mathrm{T}_{\mathrm{a}}\right)\right]\right\} 10^{-3} \quad \text { if } \quad \mathrm{w}<8 \mathrm{~ms}^{-1} \\
& \mathrm{C}_{\mathrm{h}}=\left\{1.000+\left[0.0015 \mathrm{w}\left(\mathrm{T}_{\mathrm{s}}-\mathrm{T}_{\mathrm{a}}\right)\right]\right\} 10^{-3} \quad \text { if } \quad \mathrm{w} \geq 8 \mathrm{~ms}^{-1}
\end{aligned}
$$

[18] The infrared radiation budget was computed using the formula of Bignami et al. [1995]:

$$
\left.\mathrm{Q}_{\mathrm{b}}=\varepsilon \sigma \mathrm{T}_{\mathrm{s}}^{4}-\sigma \mathrm{T}_{\mathrm{a}}^{4}(0.653+0.00535 e)\right](1+0.1762 \mathrm{C})
$$

where $e$ is the water vapor pressure, $\varepsilon$ is surface emissivity and $\sigma$ is the Stefan-Boltzman constant and $\mathrm{C}$ the cloud cover. To drive the model, daily values for each component of the heat flux are computed using the above parameterizations for the October to April of each year.

\section{Model Description}

\subsection{Model Equations}

[19] The general characteristics of the model used in this study has been described previously by Oguz et al. [1996] and Napolitano et al. [2000], who used similar versions to examine annual plankton dynamics in the Black Sea and in the eastern Mediterranean, respectively. In this coupled physical-biological model, the upper layer dynamical processes are dealt with in a one-dimensional form of the Princeton Ocean Model [Mellor, 1998] including the level 2.5 Mellor-Yamada turbulence parameterization for vertical mixing. The biological state variables considered are phytoplankton biomass $\mathrm{P}$, herbivorous zooplankton biomass $\mathrm{H}$, and labile pelagic detritus $\mathrm{D}$. Nitrate $\mathrm{N}$ and ammonium $\mathrm{A}$ constitute the other two state variables. The use of a nitrogen-based model in south Adriatic is justified by the findings of Zavatarelli et al. [1998]. The relative roles of nitrogen and phosphate limitation in this basin are still under active investigated. On the basis of the Redfield ratios, however, Zavatarelli et al. [1998] concluded that the Adriatic Sea is generally a phosphorus-limited basin, except for the surface waters in the Middle and the southern Adriatic which tend to be nitrogen-limited. Therefore the present model will predict upper limits of the biological production for the region. When the phosphate limitation is included, production values are expected to decrease to some extent.

[20] The local changes of the biological variables are expressed by a time and depth-dependent advection-diffusion equation for transport, sources and sinks in a onedimensional vertical water column. The general form of the equation is given by

$$
\frac{\partial X}{\partial t}=\frac{\partial}{\partial z}\left[\left(K_{h}+v_{h}\right) \frac{\partial X}{\partial z}\right]+F_{x}
$$

where $\mathrm{X}$ represents any of the five biological variables, $K_{h}$ is the vertical eddy diffusion coefficient computed in the model from the Mellor-Yamada level 2.5 turbulence parameterization (see Oguz et al. [1996] for details) and $v_{h}$ is its background value, $\mathrm{t}$ is time, $\mathrm{z}$ is the vertical coordinate, $\partial$ denotes the partial differentiation. $F_{x}$ represents the biological interaction terms expressed for the phytoplankton, herbivore detritus, ammonium and nitrate equations, respectively as

$$
\begin{gathered}
F_{p}=\Phi(I, N, A) P-G(P) H-m_{p} P \\
F_{h}=\gamma G(P) H-m_{h} H-\mu_{h} H \\
F_{D}=(1-\gamma) G(P) H+m_{p} P+m_{h} H-\varepsilon D+w_{s} \frac{\partial D}{\partial z}
\end{gathered}
$$


Table 2. Model Parameters Used in the Numerical Experiments ${ }^{\mathrm{a}}$

\begin{tabular}{lll}
\hline \multicolumn{1}{c}{ Parameter Definition } & Value & \multicolumn{1}{c}{ Unit } \\
\hline$A$ photosynthesis efficiency & 0.01 & $\mathrm{~m}^{2} \mathrm{~W}^{-1}$ \\
$K_{w}$ light extinction coeff. for PAR & 0.05 & $\mathrm{~m}^{-1}$ \\
$K_{c}$ phytoplankton self-shading coefficient & 0.04 & $\mathrm{~m}^{2}(\mathrm{mmol} \mathrm{N})^{-1}$ \\
$\sigma_{p}$ maximum phytoplankton growth rate & 1.0 & $\mathrm{~d}^{-1}$ \\
$m_{p}$ phytoplankton mortality rate & 0.04 & $\mathrm{~d}^{-1}$ \\
$\sigma_{g}$ zooplankton maximum grazing rate & 1.0 & $\mathrm{~d}^{-1}$ \\
$m_{h}$ zooplankton mortality rate & 0.04 & $\mathrm{~d}^{-1}$ \\
$\mu_{h}$ zooplankton excretion rate & 0.07 & $\mathrm{~d}^{-1}$ \\
$\gamma_{h}$ food assimilation efficiency & 0.75 & $\mathrm{dimensionless}$ \\
$R_{n}$ half-saturation constant in & 0.5 & $\mathrm{mmol} \mathrm{N} \mathrm{m}^{-3}$ \\
$\quad$ nitrate uptake & 0.2 & $\mathrm{mmol} \mathrm{N} \mathrm{m}^{-3}$ \\
$R_{a}$ half-saturation constant in & & \\
$\quad$ ammonium uptake & 0.5 & $\mathrm{mmol} \mathrm{N} \mathrm{m}^{-3}$ \\
$R_{g}$ half-saturation constant for & & \\
$\quad$ zooplankton grazing & 3 & $\left(\mathrm{mmol} \mathrm{N} \mathrm{m}^{-3}\right)^{-1}$ \\
$\psi$ ammonium inhibition parameter & & \\
$\quad$ of nitrate uptake & 0.1 & $\mathrm{~d}^{-1}$ \\
$\varepsilon$ detritus decomposition rate & 10.0 & $\mathrm{~m} \mathrm{~d}^{-1}$ \\
$w_{s}$ detrital sinking rate & 0.05 & $\mathrm{~d}^{-1}$ \\
$\Omega_{A}$ nitrification rate & 0.1 & $\mathrm{~cm}^{2} \mathrm{~s}^{-1}$ \\
$v_{b}$ background kinematic diffusivity &
\end{tabular}

a Note: $\mathrm{mmol} \mathrm{m}^{-3}$ is equivalent to $\mu \mathrm{mol} \mathrm{L}-{ }^{1}$.

$$
\begin{gathered}
F_{A}=-\Phi_{A}(I, A) P+\mu_{h} H+\varepsilon D-\Omega A \\
F_{N}=-\Phi_{N}(I, N) P+\Omega A
\end{gathered}
$$

A more extensive definition of the function in the equations is given by Napolitano et al. [2000]. The parameters used for this study are enumerated in Table 2 .

[21] It should be noted that equation (2) implies that the variations of phytoplankton stock are governed by a balance between primary production and losses due to herbivore grazing and mortality. A certain fraction of the food grazed by herbivores is assimilated (represented by the first term in equation (3)) and the rest is egested as fecal pellets to the detrital pool (the first term in equation (4)). Mortality and excretion are two forms of herbivore losses from the system (the second and third terms of equation (3)). The dead planktonic material (the second and third terms of equation (4)) constitutes an additional detritus source. This material sinks with a speed $\mathrm{w}_{\mathrm{S}}$ and, at the same time, is remineralized and converted to ammonium. These two processes are represented by the last two terms in equation (4). The zooplankton excretion and remineralization of detritus form the ammonium sources in equation (5). Ammonium is consumed by phytoplankton growth and converted to nitrate by the nitrification processes. The nitrate equation (equation (6)) represents a balance between nitrate input through the nitrogen recycling mechanism and its uptake for phytoplankton growth.

\subsection{Boundary Conditions}

[22] The momentum equation and the temperature and salinity equations are subject to following boundary conditions at the air-sea interface:

$$
\begin{gathered}
\rho_{0} \mathrm{~K}_{\mathrm{m}}(\partial \mathrm{u} / \partial \mathrm{z}, \partial \mathrm{v} / \partial \mathrm{z})=\left(\tau_{\mathrm{u}}, \tau_{\mathrm{v}}\right) \\
\mathrm{K}_{\mathrm{h}}(\partial \mathrm{T} / \partial \mathrm{z})=\mathrm{Q}_{\mathrm{tot}} / \rho_{0} \mathrm{C}_{\mathrm{p}} \\
\mathrm{S}=\mathrm{S}_{0}
\end{gathered}
$$

where $\mathrm{K}_{\mathrm{m}, \mathrm{h}}$ are the mixing coefficients obtained using the level 2.5 Mellor and Yamada [1982] turbulence closure scheme, $\mathrm{Q}_{\text {tot }}$ is the total air-sea interface heat budget, $\tau_{\mathrm{u}}$ and $\tau_{\mathrm{V}}$ are the wind stress components, $\rho_{0}$ is water density and $\mathrm{S}_{0}$ is surface salinity. The last boundary condition means that the salinity is restored to $\mathrm{S}_{0}$ in the top grid layer with an infinite restoring time.

[23] The surface heat fluxes were computed from ECMWF data using bulk parameterization formulas as described in section 2.2. Wind stress time series were calculated from ECMWF winds using the following wind intensity-dependent parameterization:

$$
\tau=\rho_{a} \mathrm{C}_{D}|\mathbf{W}| \mathbf{W}
$$

where $\rho_{\mathrm{a}}$ is the air density, $\mathbf{W}$ is the wind vector, and the drag coefficient is [after Smith, 1980]:

$$
\mathrm{C}_{\mathrm{D}}=10^{-3} \quad \text { if }|\mathbf{W}| \leq 6 \mathrm{~m} \mathrm{~s}^{-1}
$$

$$
\begin{gathered}
\mathrm{C}_{\mathrm{D}}=(0.61+0.063|\mathbf{W}|) 10^{-3} \quad \text { if } 6 \mathrm{~m} \mathrm{~s}^{-1}<|\mathbf{W}| \leq 22 \mathrm{~m} \mathrm{~s}^{-1} \\
\mathrm{C}_{\mathrm{D}}=2 \times 10^{-3} \quad \text { if }|\mathbf{W}|>22 \mathrm{~m} \mathrm{~s}^{-1}
\end{gathered}
$$

As a surface boundary condition, the time-dependent sea surface salinity was used. To obtain a suitable boundary condition, climatological monthly averages of surface salinity were computed using all MED6-MODB salinity profiles in the SAG. Sensitivity experiments performed by varying salinity by one standard deviation indicated no substantial effects on the year-to-year mixed layer deepening.

[24] Concerning the biochemical model no-flux conditions described by

$$
\left(K_{h}+v_{h}\right) \frac{\partial X}{\partial z}=0
$$

are specified both at the surface and the bottom boundaries of the model for the variables $\mathrm{X}=\mathrm{P}, \mathrm{H}, \mathrm{N}$ and $\mathrm{A}$. For detritus it is modified to include the contribution of downward sinking flux

$$
\left(K_{h}+v_{h}\right) \frac{\partial D}{\partial z}+w_{s} D=0
$$

[25] The bottom boundary of the model is taken at the $1000 \mathrm{~m}$ depth, which is well below the euphotic zone comprising only the upper $100 \mathrm{~m}$ of the water column. Following previous works we choose moderate detritus sinking rates (see Table 2). The advantage of locating the bottom boundary at considerable distance away from the euphotic layer is to allow complete remineralization of the detrital material prior to reaching the lower boundary of the model. This approach avoids prescription of the nonzero flux boundary condition in order to compensate the loss of detritus (if any) to the deep interior from the boundary. The assumption of complete mineralization is introduced here as a convenience. Within the framework of 
one-dimensional model, if it is relaxed, particulate matter export flux to deeper parts of the sea must be compensated by influx of nitrate at the base of the model at each time step. This is almost identical to converting all particulate matter into nitrate form within the lower part of the water column. In the three-dimensional case, the situation is different and particulate matter loss may be compensated by lateral fluxes. The complete remineralization was ensured by setting appropriate decomposition and sinking rates of detrital material in the model. We note that equations (2)-(6) together with the boundary conditions (7) and (8) provide a closed, fully conserved system. The state of the system at time $t$ is governed solely by internal dynamical processes without any contribution from external sources.

[26] The PAR is taken as the half of the incoming solar irradiance by ECMWF (see section 2). It is introduced in the model by the light limitation parametrization as described by Napolitano et al. [2000].

\subsection{Initial Conditions}

[27] The October climatological temperature and salinity profile from MED6-MODB [Brankart and Pinardi, 1980] was used to initialize the model. The initial profile is relevant to deepwater formation because the density distribution determines the amount of surface buoyancy loss required to destabilize the water column, and as a consequence, the mixing depth and density-compensated temperature/salinity variations that influence the properties of the newly formed deep water [Mertens and Schott, 1998]. However, since preconditioning profiles for each study year were not available, all runs were performed using the same initial temperature and salinity profile. Consequently, we can only investigate the year-to-year variability of the vertical mixing and water properties due to the variability of the local atmospheric forcing.

[28] In the biological model, the initial nitrate amount drives the system as it is entrained and diffused upward and utilized ultimately for the biological production. In the absence of any external source and sink as implied by the boundary conditions (see equations (7) and (8)), the model simply redistributes the initial nitrogen source among the living and nonliving components of the system. Thus specification of the initial phytoplankton, zooplankton, detritus, and ammonium distribution is unimportant as they will be generated by the model during its transient evolution (adjustment phase). The initial subsurface nitrate structure however will govern, to a large extent, the level of productivity in the euphotic zone. Accordingly, the state of variables except nitrate are initialized by a vertically uniform small, nonzero value within the euphotic layer. The initial vertical nitrate structure (Figure 2) are specified according to the data given by Zavatarelli et al. [1998] and adjusted in accordance with observations made during our study period by Civitarese and Gacic [2001]. Their data shows that from 1995-1997, nitrogen concentration below the nutricline (integrated from $\sim 200$ to $800 \mathrm{~m}$ ) is about $\sim 5.2$ in the SAG center.

\subsection{Numerical Procedure}

[29] The model equations are solved using the finite difference procedure described by Mellor [1998]. A total of 71 layers are used to resolve the water column. The grid
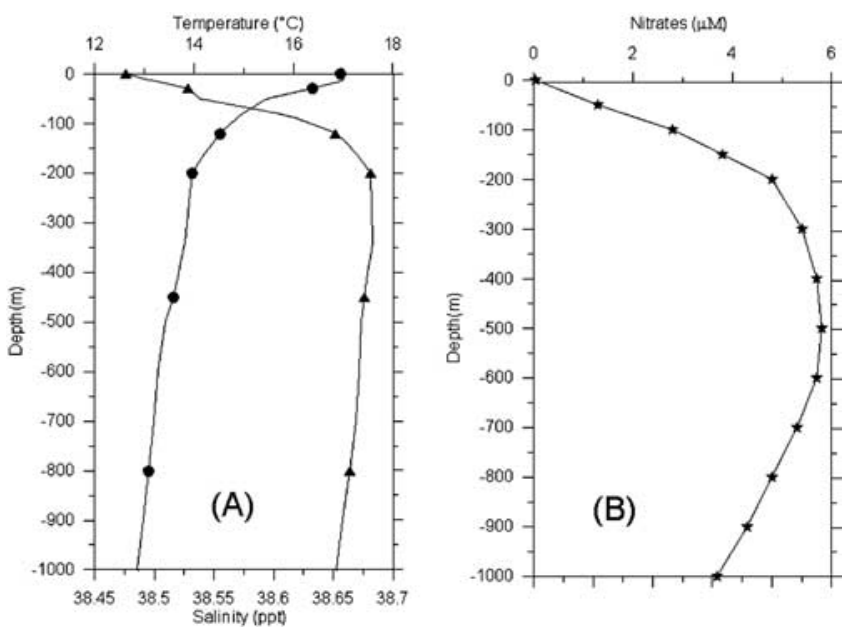

Figure 2. Initial temperature (dots), salinity (triangles), and nitrate (stars) profiles used to initialize model.

spacing is compressed toward the surface to increase the resolution within the euphotic zone. The vertical grid spacing is almost $10 \mathrm{~m}$. This resolution is found to be quite adequate to represent properly steep gradients of density and nitrate between the seasonal thermocline/pycnocline and the base of euphotic zone. The numerical scheme is implicit to avoid computational instabilities due to small grid spacing and is fully documented by Mellor [1998]. A time step of $5 \mathrm{~min}$ is used in the numerical integration of the equations, and provides a stable solution without introducing numerical noise. The biological model is first integrated in constant October conditions ( 30 days) in order to reproduce a distribution of the state variables such as $\mathrm{P}, \mathrm{H}, \mathrm{D}, \mathrm{A}$ consistent with the initial nitrates profiles. The physical model run is performed from October to the end of April using each year's forcing. Then the biological model is run coupled with the physical model forward in time for seven months from October to April for the three respective years: 1997-1998, 1998-1999, and 1999-2000, within the temporal window covering the deep convection mechanism and the spring bloom events.

\subsection{Choice of the Parameters}

[30] The parameters used in the simulations (Table 2) are chosen from the available data and from the literature relating to either general Mediterranean ecosystem modeling [Crise et al., 1998; Lévy et al., 1998; Napolitano et al., 2000] or specific to Adriatic Sea modeling [Zavatarelli et al., 2000; Allen et al., 1998]. The values of extinction coefficient $(\mathrm{Kw}, \mathrm{Kc})$ that are used in the model represent typical optical properties observed in Mediterranean offshore waters and have been used in previous ecosystem modeling studies. The phytoplankton parameters chosen are typical of diatoms: $1 \mathrm{~d}^{-1}$ for the maximum growth rate, $0.04 \mathrm{~d}^{-1}$ for the overall contribution of natural mortality and excretion. The parameters for the herbivores are adjusted according to mesozooplankton physiological parameters. Hence the maximum grazing, mortality and excrection rates are taken as 1, 0.04, and $0.04 \mathrm{~d}^{-1}$, respectively. As discussed later (section 7), our sensitivity experiments suggest the choice of a phytoplankton growth rate that is equal to the maximum zooplankton grazing rate seems to be 
appropriate for representing the overall response of the SAG system. The effect of the use of grazing rates as a fraction of phytoplankton growth rate is also discussed in section 7 . The detritus breakdown rate is $0.1 \mathrm{~d}^{-1}$ being more appropriate for the small-to-moderate size particles sinking with a constant rate of $10 \mathrm{~m} \mathrm{~d}^{-1}$. The nitrification rate is $0.05 \mathrm{~d}^{-1}$. Assumption of constant nitrification rate is more appropriate for the deeper part of the water column. In the euphotic zone, nitrification is light limited, and does not play a major role. The nitrogen pool in the phytoplankton stock is then converted in chlorophyll $a$ values using the typical Redfield ratio $(\mathrm{C}: \mathrm{N}=6.5)$ and $\mathrm{C}: \mathrm{Chl} a=100$ as suggested in SAG.

\section{Year-to-Year Variability of SeaWiFS Chlorophyll Imagery}

[31] In this section, we examine the time series of satellite images by year in order to describe the chlorophyll pattern from the beginning of the year to the end bloom period. Rather than showing images at regular intervals, significant phases of the bloom and its rapid evolution are shown in Figures 3, 4, and 5. common pattern present in each year is the occurrence of low chlorophyll concentrations immediately preceding the bloom onset (see Figure 6), but the timing and intensity of these events vary from year to year.

\subsection{Year 1998}

[32] The chlorophyll concentrations in the SAG were moderate for January (Figure 3), i.e., on the order of $0.4 \mathrm{mg}$ $\mathrm{m}^{-3}$. For most of January, it is difficult to observe the SAG in its entirety, but areas between the clouds were characterized by unchanging chlorophyll values except for low values on 23 January, when strong winds from the northeastern induced significant heat losses over the area (Figures 7a and 8a). Advection of chlorophyll-rich Albanian coastal water is observed in 9-10 February, which probably contributed to the phytoplankton increase $\left(>0.6 \mathrm{mg} \mathrm{m}^{-3}\right)$ in the SAG interior by 14 February. This early bloom is dispersed by another brief wind event (19 February), but high-chlorophyll patches rapidly reform (21 February). The southerly patch becomes better developed with pigment concentrations reaching $2.0 \mathrm{mg} \mathrm{m}^{-3}$ (27-28 February). Small-scale features probably associated with the cyclonic flow of the SAG form (2-6 March), after which the bloom weakens. The next days are cloudy (7-11 March) but areas visible through cloud gaps suggest the feature has been smeared by winds.

[33] In the next sequence of images, an asymmetric lowchlorophyll area $\left(<0.1 \mathrm{mg} \mathrm{m}^{-3}\right.$; referred to as a "hole" hereafter), appears (17-28 March). The "hole" is initially not well-defined but becomes highlighted as pigment concentrations increase on the eastern meandering edge (2328 March; see Figure $6 \mathrm{~b}$ for an enlargement). The maximum chlorophyll concentration at the border of the "hole" is consistent with in situ observations and simulations of convective areas [Nival et al., 1972, 1975; Lévy et al., 1999]. These meanders are on the order of $30-40 \mathrm{~km}$, which are comparable to those typically occurring at the edge of deep convective regions immediately after the violent mixing phase [Marshall and Schott, 1999; Lévy et al., 2000]. According to Killworth [1983], these meanders play and important role in the sinking and spreading of water masses by sinking dense water out of the convective zone and by upwelling lighter peripheral water toward the center. Thus these mesoscale instability is responsible for the collapse of the dense water patch and restratification of the water column [Jones and Marshall, 1997]. Within 2 days, the "hole" has disappeared (30 March), consistent with the idea that the propagation of the mesoscale instabilities lead to the rapid closure of the convective area. By 1 April, a large central bloom $\left(>1.5 \mathrm{mg} \mathrm{m}^{-3}\right)$ covers most of the SAG. It is more spatially extensive than the February bloom, and high pigments are observed until 5 April. The bloom is no longer visible a week later (15 April) and no further increases occur over the rest of the month.

\subsection{Year 1999}

[34] Unlike the previous year, the low-chlorophyll "hole" is observed from the start of the year and persists for several weeks in the 1999 imagery (Figure 4; 7-27 January). Minimal chlorophyll patches discernible on 7 January quickly develop into a large "hole" with meandering edges by 16 January. The shape of the "hole" varies over the next few weeks (5-27 February). In 27 February (Figure 6a) the "hole" is more than $50 \mathrm{~km}$ across which is the consistent with the size of a mixed convective patch [Marshall and Schott, 1999]. The 2 month persistence of the "hole" resulted in much lower chlorophyll concentrations compared to that of the previous year for the same dates. Chlorophyll concentrations above $0.5 \mathrm{mg} \mathrm{m}^{-3}$ were not observed in the central area until 3 March, when mesoscale patches of high chlorophyll appear. Because of a sequence of wind effects, these patches become smeared and almost completely disappear in the next few days (5-10 March), then reform but shift around, eventually stabilizing in a more northerly position (12-21 March). The interruption and redistribution of a bloom by wind bursts has been observed in other locations and reproduced in simulations [Townsend et al., 1994, 1992; Lévy et al., 2000]. The bloom is initially more intense in the northern part of the SAG (24 March), then becomes more widespread, covering most of the center, highlighted by the contrasting oligotrophic Ionian Seawater inflow (25 March to 7 April). The asymmetrical development of the bloom area (see also Figure 6c for a zoom) can be induced by wind forcing, because Ekman transport has a wider extent and is more efficient in the direction perpendicular to the wind relative to ongoing baroclinic processes, as demonstrated by Lévy et al. [2000]. The surface chlorophyll concentrations reach a maximum around 30 March (Figure 4), then slowly decline even though the meandering structure is preserved (17 April). Although the structure dissipates by 12 April, traces of elevated chlorophyll $\left(\sim 0.5 \mathrm{mg} \mathrm{m}^{-3}\right)$ remain (26 April).

\subsection{Year 2000}

[35] The image time series for 2000 differs from the previous years in that, except for a few days, pigments levels were below $0.2 \mathrm{mg} \mathrm{m}^{-3}$ from January to March (Figure 5). Although a low-chlorophyll area was easily identifiable in the images, the location was neither central nor fixed. Instead, the "hole" shifted around. First, the asymmetric "hole" developed in the SAG center (2029 January). Then, the minimal chlorophyll area briefly disappeared (1 February), reappearing east along the Croa- 
PBE $23-8$ SANTOLERI ET AL.: PHYTOPLANKTON BLOOM IN SOUTHERN ADRIATIC SEA

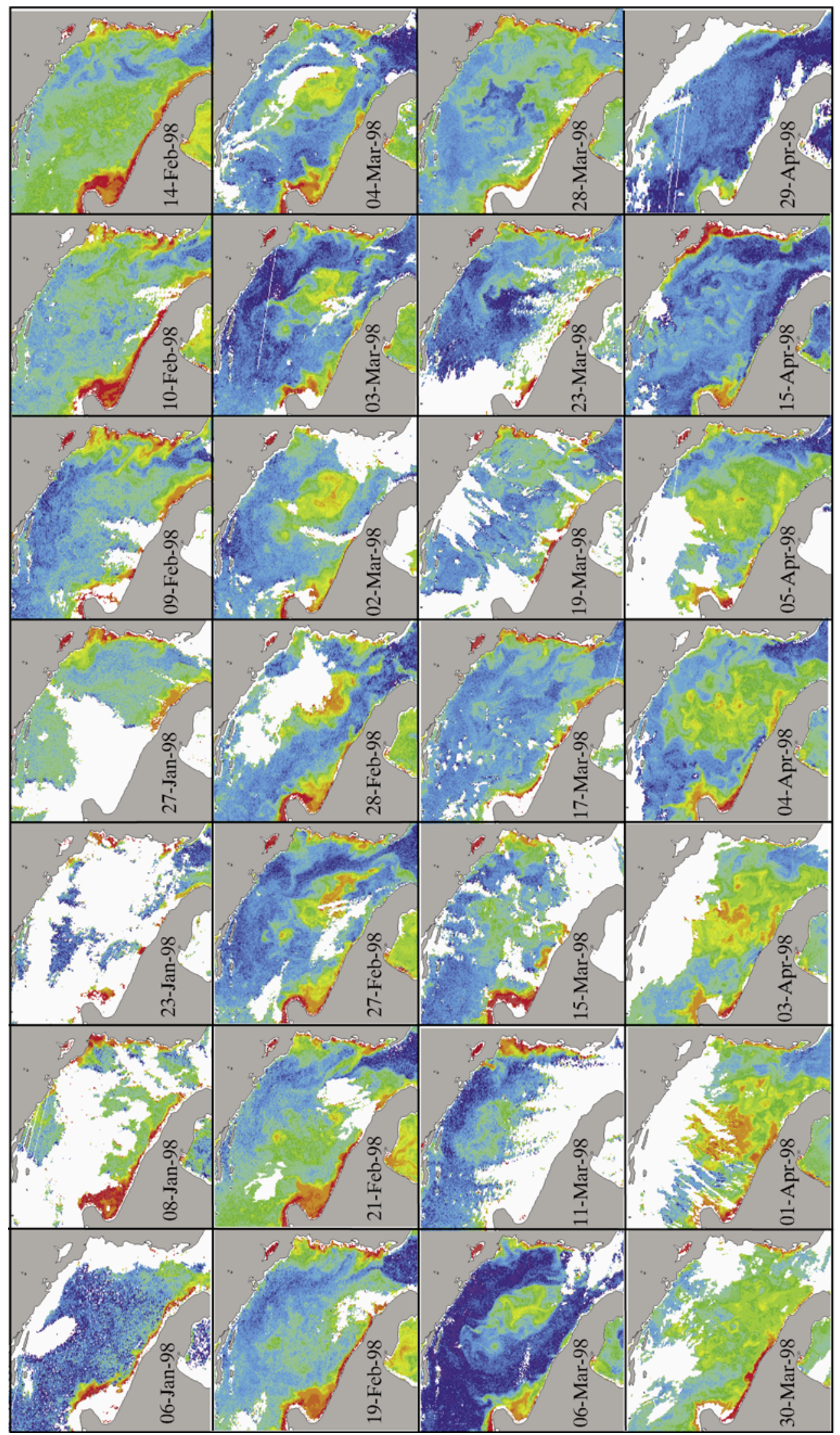

$\frac{5}{5}$

ह

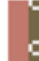

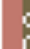

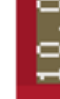

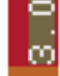

เin.

$\because \quad$

家.

- 4

‥

夏

틀

음

1

는

.

量

는

응

뷴

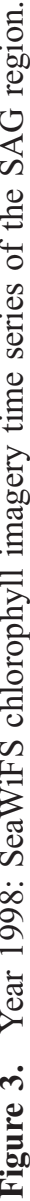

늠

$\frac{0}{\sqrt[U]{U}}$ 


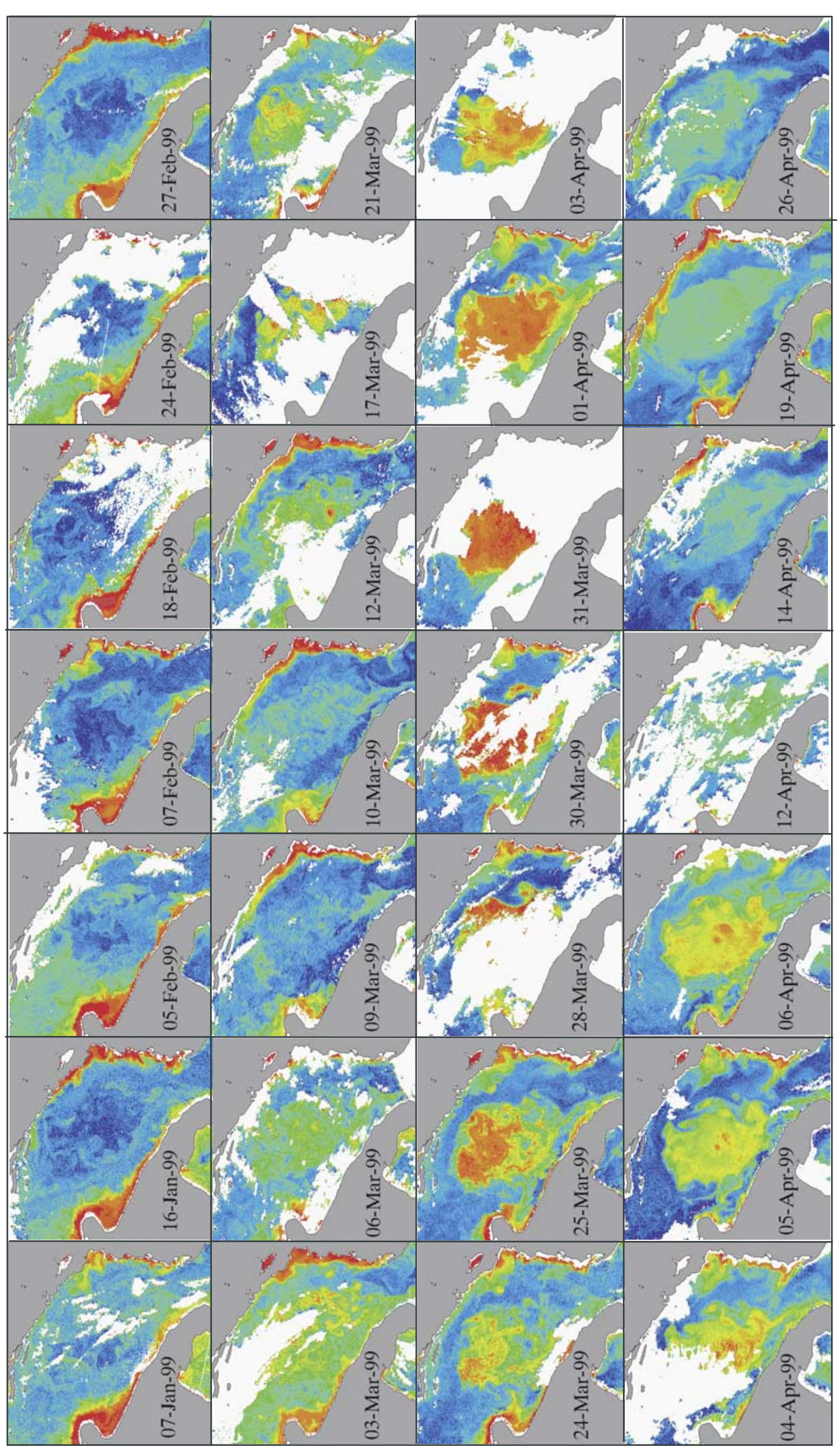


PBE 23 - 10 SANTOLERI ET AL.: PHYTOPLANKTON BLOOM IN SOUTHERN ADRIATIC SEA

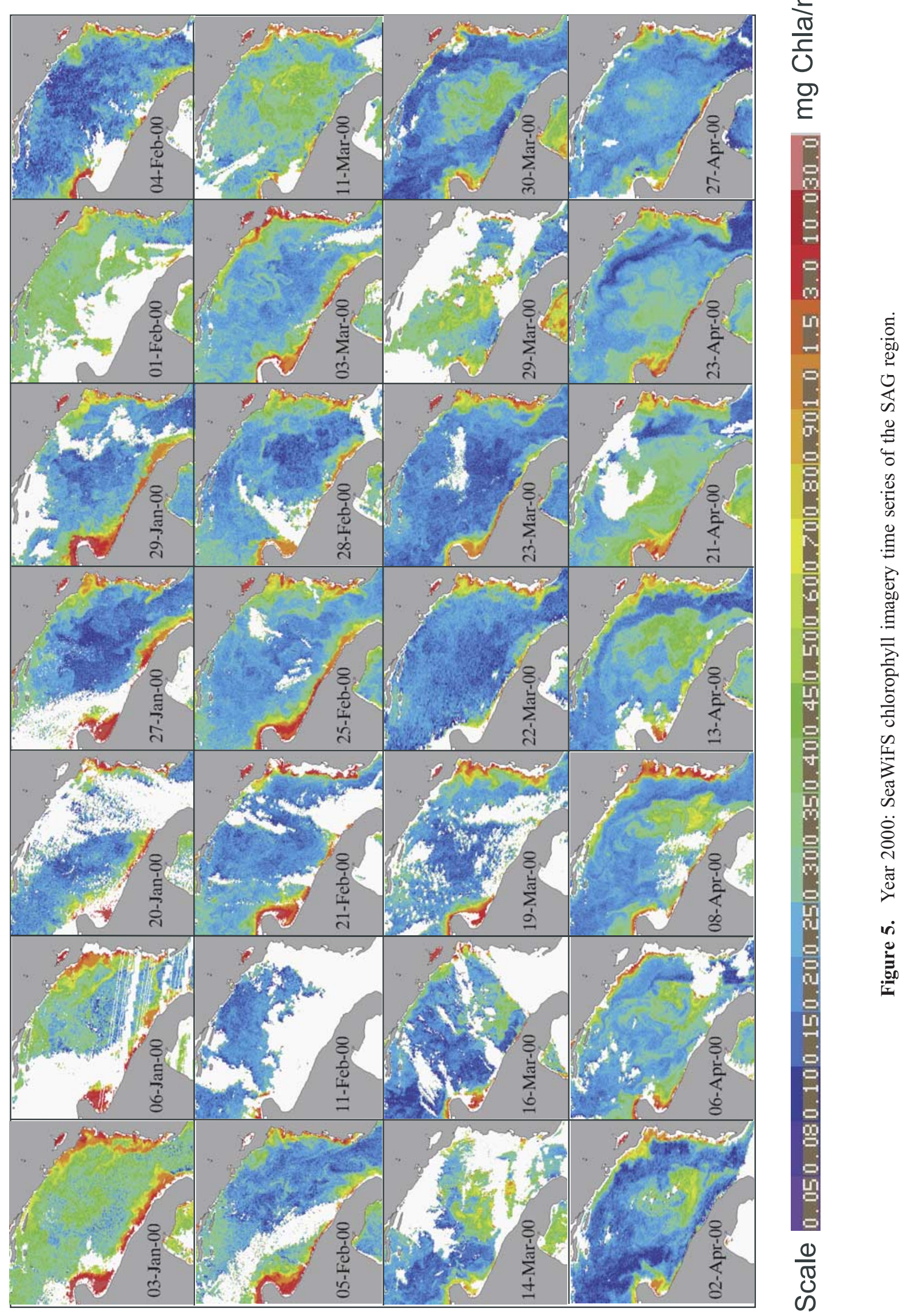


tian coast (4 February), then becoming less distinguishable again (5-25 February). By 28 February, the "hole" was centrally located but southward toward the Otranto Straits. These changes in location were probably linked to a shifting

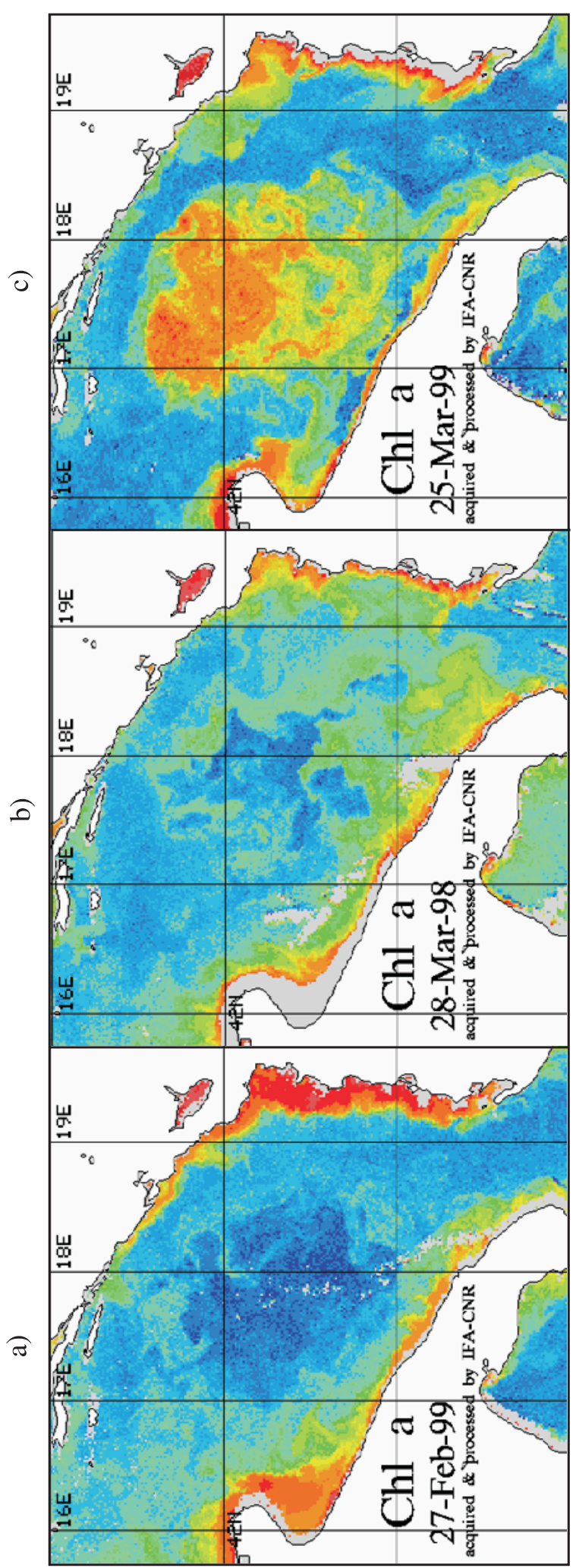

wind field. The subsequent clear images (28 February to 14 March) show rapid closure of the "hole" and chlorophyll concentrations increasing toward the center over time. However, the bloom onset, marked by an increase in chlorophyll concentrations above $0.6 \mathrm{mg} \mathrm{m}^{-3}$ (11-14 March), was interrupted by the appearance of another "hole" (1923 March). By 29 March, the bloom has resumed but, unlike the previous years, concentrations do not exceed $0.6 \mathrm{mg} \mathrm{m}^{-3}$. The highest chlorophyll patch was located at a very southerly location and later propagated northward inside the SAG following the rotation of the gyre (30 March to 23 April). By 27 April the bloom has dissipated.

\section{Simulated Interannual Variability of the Mixed Layer and Ecosystem Dynamics}

[36] In this section, each year's convective conditions are described by examining net heat fluxes (Figure 8 ) from the preceding fall to early spring, and their effect on the vertical water column structure as simulated by the mixed layer model. The temporal evolution of modeled density profiles (Figure 9) make it possible to examine the progressive deepening of the mixed layer over the preconditioning phase (November-February), the depth and timing of maximum convective penetration during the violent mixing phase, and the restratification process, both ephemeral and seasonal. The ecological response to physical process is described mainly in terms of the nitrates and phytoplankton which can easily be related to SeaWiFS data and other previous in situ measurements in the study area. The zooplankton, ammonium and detritus components are also shown even though there is no data available to validate the model results (Figures 11-13).

\subsection{October 1997 to April 1998}

[37] The heat fluxes (Figure 8a) illustrate the daily variability superimposed on seasonal behavior (positive or negative flux). Negative fluxes predominate from November to March, followed by mostly positive heat exchange after the vernal equinox. Net heat fluxes from fall 1997 to winter 1998 (upper panel) show the smallest airsea exchanges of the three years. Over the preconditioning period (from November to mid-February), the daily $\mathrm{Q}_{\text {tot }}$ rarely went below $-250 \mathrm{~W} \mathrm{~m}^{-2}$ and averaged about $-120 \mathrm{~W} \mathrm{~m}^{-2} \mathrm{~d}^{-1}$. This moderate preconditioning heat loss resulted in the progressive homogenization of the modeled water column down to only $\sim 200-250 \mathrm{~m}$ (Figure 9a), which reaches the nutricline. By the end of February, the modeled water column restratifies as fluxes become positive. However, between 10 and 23 March, the most significant heat losses for this year occur, with northerly cold and dry winds inducing heat losses of up to $300 \mathrm{~W} \mathrm{~m}^{-2}$ in single day. Corresponding to this event, the modeled water column again is mixed down to about 200-250 m (Figure 9a). In

Figure 6. (opposite) Principal phases of the south Adriatic phytoplankton bloom onset following deep convection: (a) chlorophyll minimum feature at the end of the deep convection phase, (b) contracted chlorophyll minimum with enhanced chlorophyll at the meandering edges, and (c) final phase of the bloom onset: well developed spring bloom. 

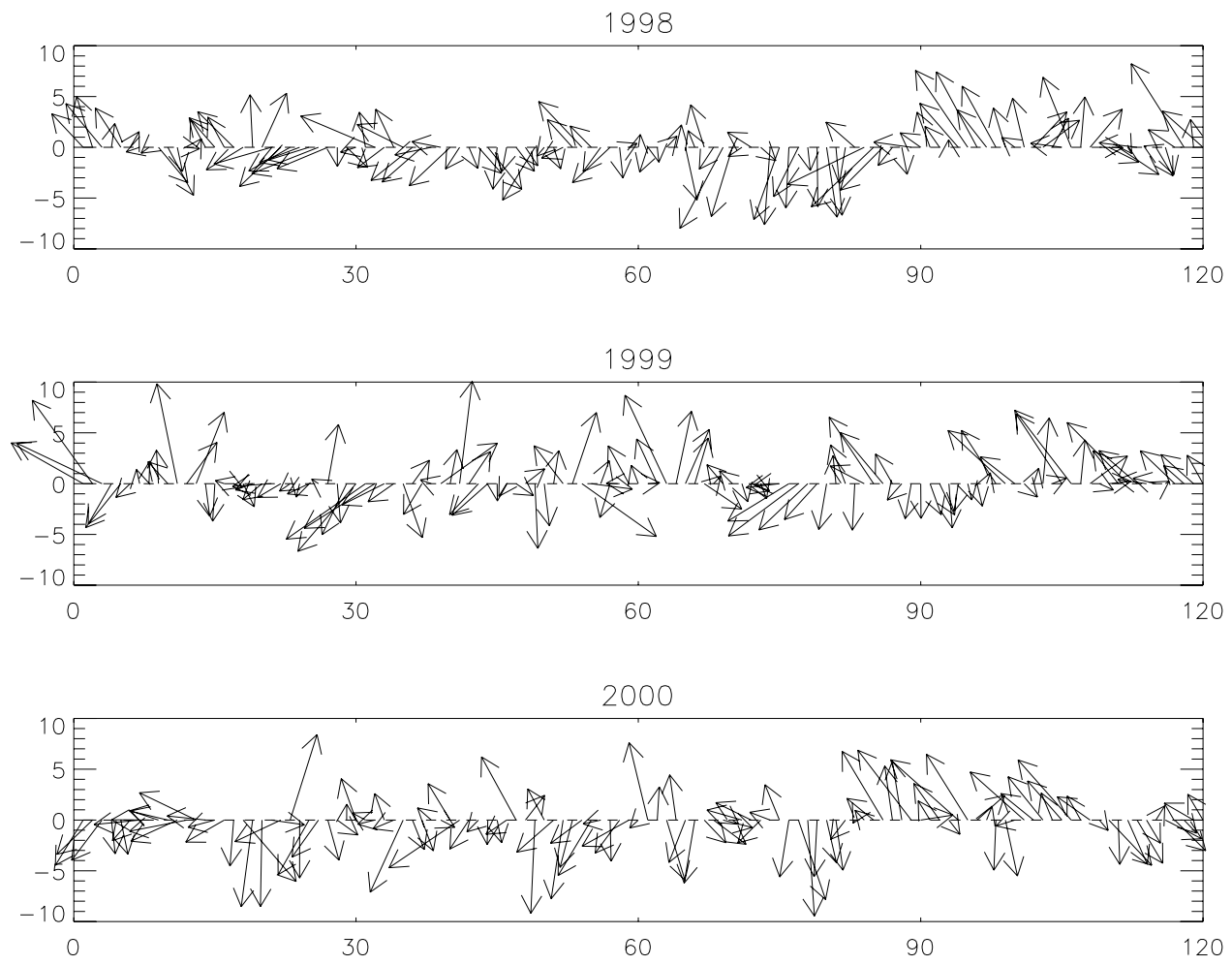

Figure 7. Stick diagram of the wind in the center $\left(41.7^{\circ} \mathrm{N}, 17.9^{\circ} \mathrm{E}\right)$ of the SAG from ECMWF data.

April, predominantly positive heat fluxes result in reconstruction of the modeled thermocline.

[38] In agreement with vertical mixing and stratification evolution, the nitrate structure undergoes considerable variations from autumn to spring (Figure 10a). Starting with nutrient poor conditions $(<0.25 \mu \mathrm{M})$ the mixed layer becomes progressively enriched as it deepens. At the beginning of January nitrate concentrations are less the $1.0 \mu \mathrm{M}$ and increase to $2.0 \mu \mathrm{M}$ at the end of month, in agreement with in situ measurements made in the center of the gyre on 3 and 28 January by Civitarese and Gacic [2001]. The highest nitrate concentration occurs in middle February $(\sim 2.25 \mu \mathrm{M})$ after which nutrients are used up as the phytoplankton bloom begins (Figure 11a). The second mixing event replenishes the upper layer nitrate, which supports a second but smaller bloom. For the end of March, Gacic et al. [2002] reports homogenization of the water column to $300 \mathrm{~m}$. Maximum nitrate concentration were about $4 \mu \mathrm{M}$ and surface density was $\sigma \sim 29.10-29.15$ [Civitarese and Gacic, 2001; Manca et al., 2002]. Compared to these observations, the model produced slightly shallower mixing depths but smaller density values $(\sigma \sim$ 29.04), and lower surface nitrate concentrations.

[39] The characteristics of two phytoplankton blooms produced by the model (Figure 11a) are largely determined by the nutrients, light availability and stability of the water column. The first bloom lasts for 2 weeks and reaches a maximum surface concentration of $>2 \mu \mathrm{M} \mathrm{N}$ in the first $20 \mathrm{~m}$. The bloom initiates other biological processes within the living and nonliving components of the pelagic ecosystem. The meso-zooplankton biomass increases about a week after the bloom starts. An increase in detritus and ammonium concentration occurs because of the excretion

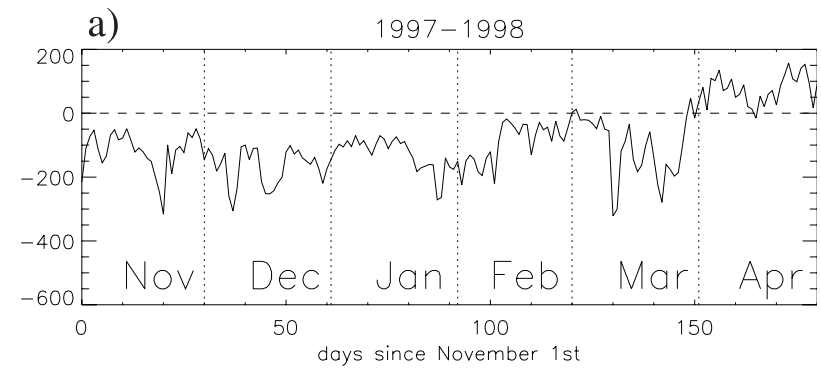

b)

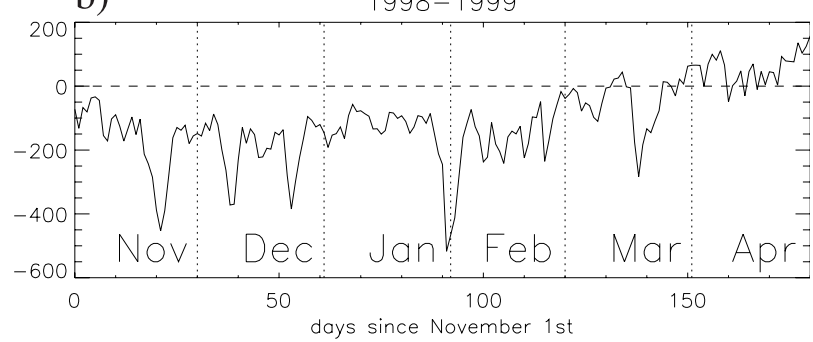

c) $1999-2000$

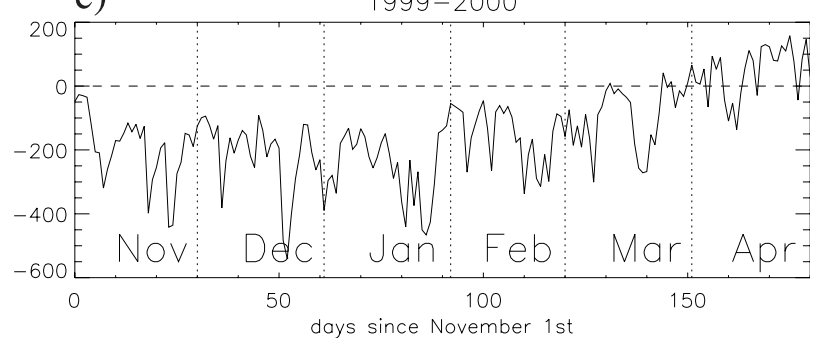

Figure 8. Time series of the total heat fluxes in the center $\left(41.7^{\circ} \mathrm{N}, 17.9^{\circ} \mathrm{E}\right)$ of the SAG computed from ECMWF data: (a) November 1997 to 30 April 1998, (b) 1 November 1998 to 30 April 1999, and (c) 1 November 1999 to 30 April 2000. 

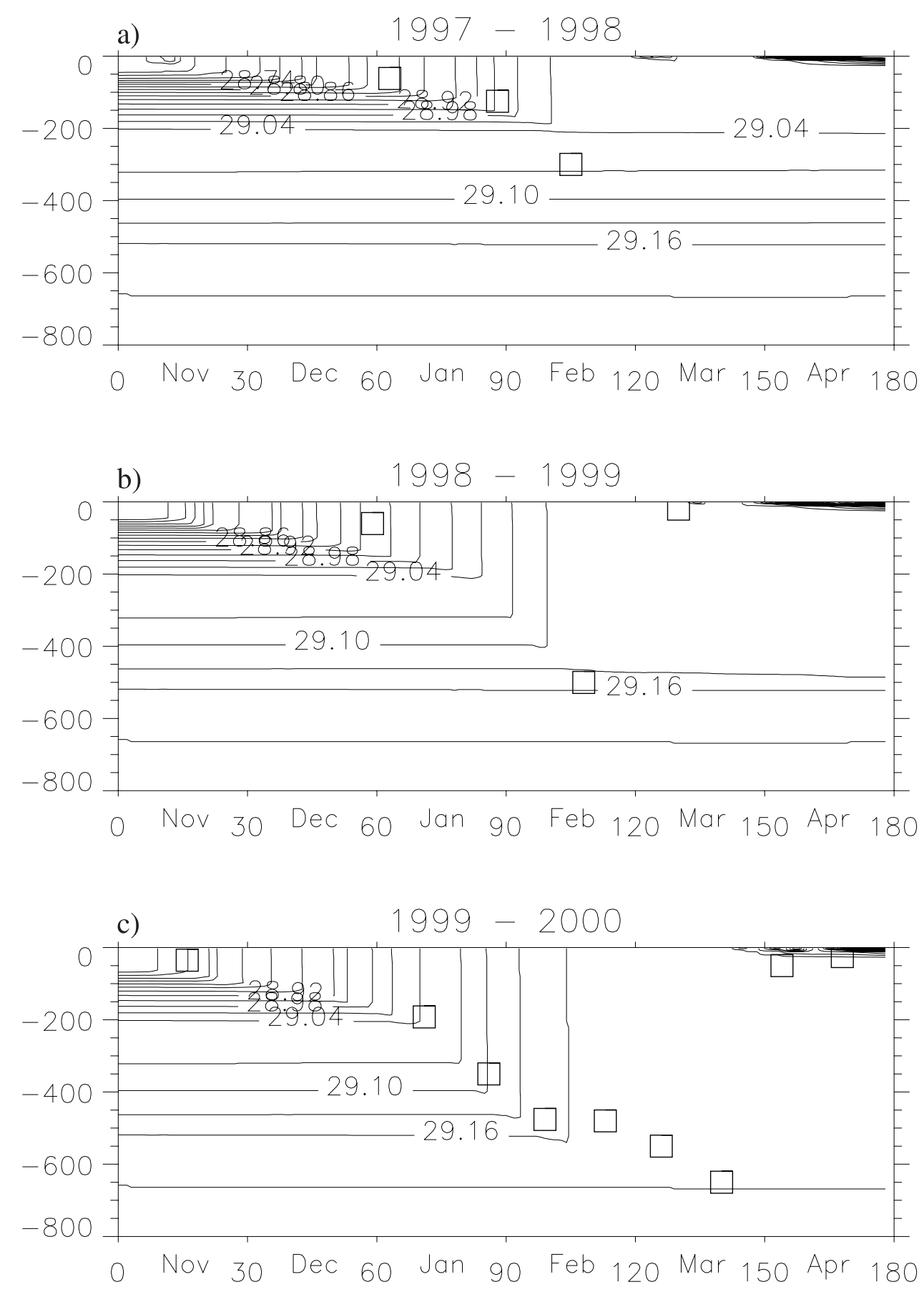

Figure 9. The model-simulated water column density in the SAG center. Density contour interval is 0.03 б0: (a) 1 November 1997 to 30 April 1998, (b) 1 November 1998 to 30 April 1999, and (c) 1 November 1999 to 30 April 2000. Squares indicate mixed layer depths as derived by XBT observations (year 2000) and published CTD measurements (year 1998/1999; see text).

and mortality of phytoplankton and zooplankton communities. Detritus initially accumulates near the surface, then becomes dispersed to greater depth as zooplankton grazing becomes more important.

[40] The second bloom is limited to first $20 \mathrm{~m}$ and lasts for only a week with maximum biomass of $\sim 0.75 \mu \mathrm{M} \mathrm{N}$. Compared to the zooplankton biomass during the first bloom, grazers are more abundant at the onset and during the second bloom, and tended to be restricted to the upper $40 \mathrm{~m}$. The detritus also has a more limited vertical extent.
The role of remineralization for transforming the particulate $\mathrm{N}$ to inorganic dissolved $\mathrm{N}$ is indicated by the increase of ammonium concentrations $(0.12$ for the first bloom and much greater for the second bloom).

\subsection{October 1998 to April 1999}

[41] In 1998-1999, net heat fluxes were about double that of the previous year. Over the preconditioning period (November 1998 to February 1999), daily Q tot averaged $-155 \mathrm{~W} \mathrm{~m}^{-2}$ (Figure 8b). Significant heat loss events 


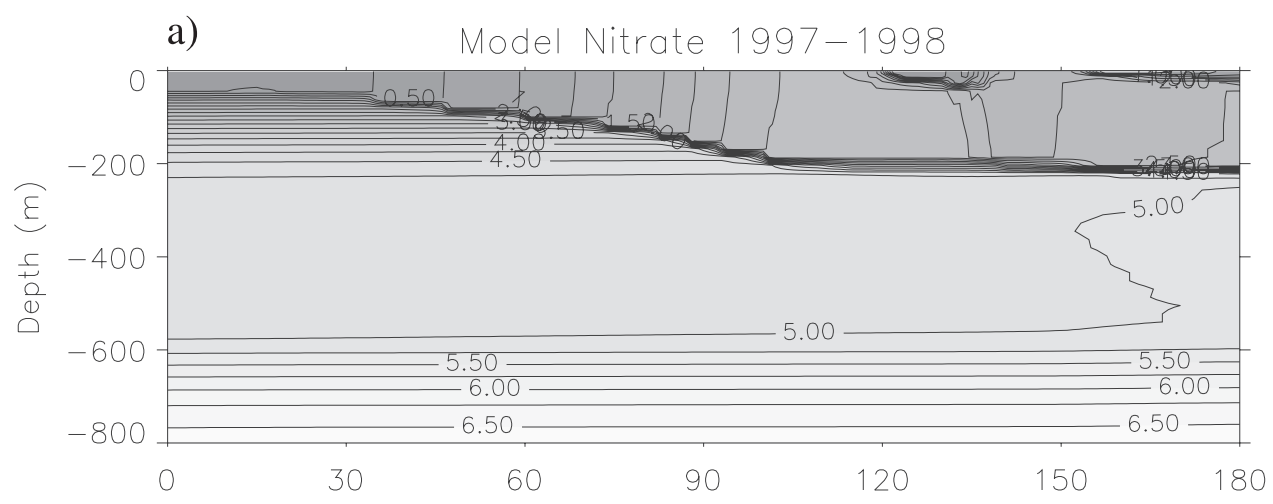

b)

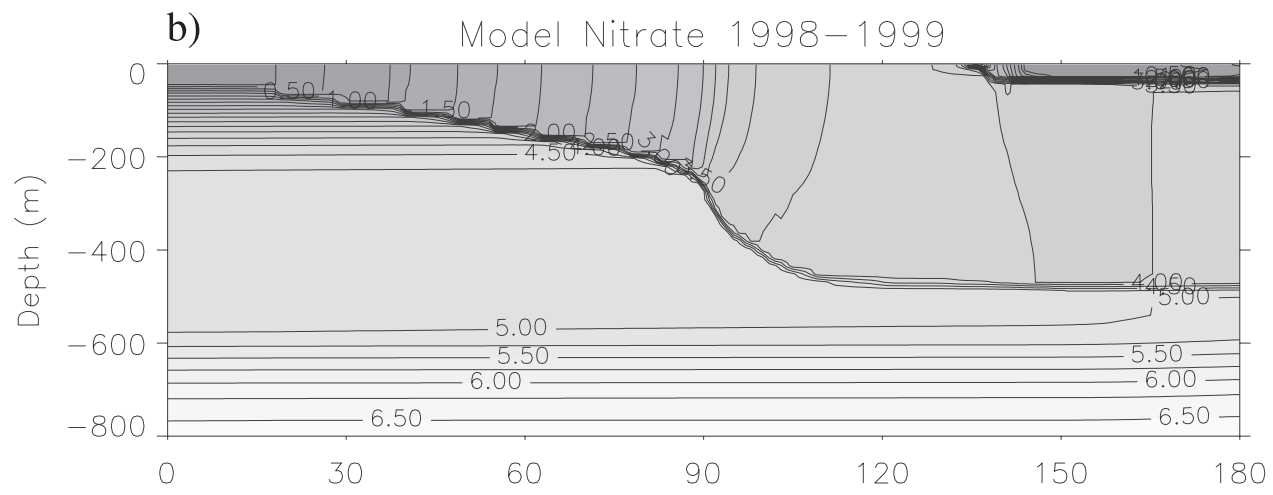

c)

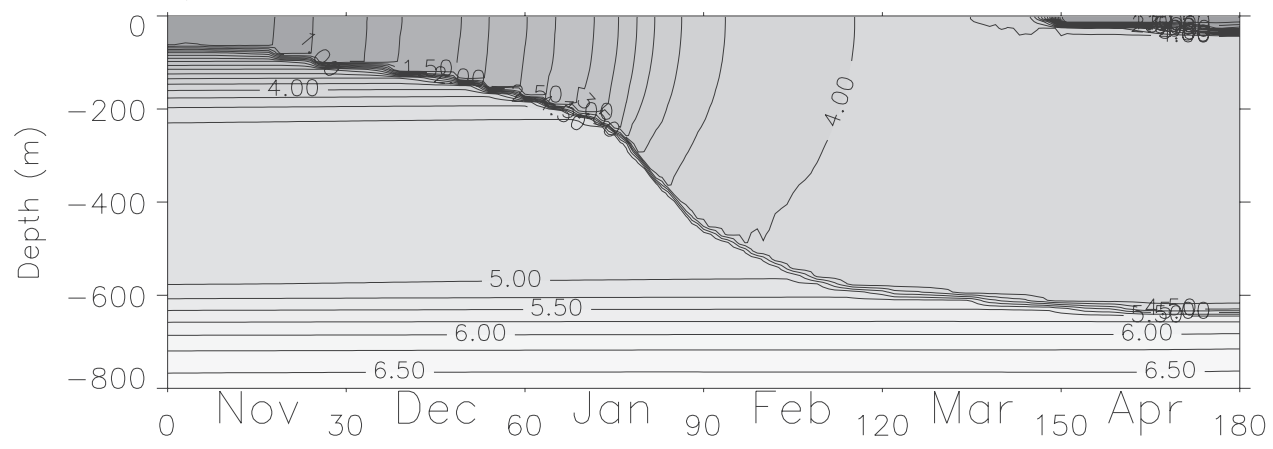

Figure 10. The model simulation of the nitrate concentration in the SAG center: (a) 1 November 1997 to 30 April 1998, (b) 1 November 1998 to 30 April 1999, and (c) 1 November 1999 to 30 April 2000. Nitrates contour interval is $0.4 \mu \mathrm{M}$.

occurred in the beginning of December $\left(\sim-400 \mathrm{~W} \mathrm{~m}^{-2}\right)$ and early February $\left(\sim-500 \mathrm{~W} \mathrm{~m}^{-2}\right)$ after a sequence of intense N-NE wind bursts. This forcing resulted in a continuous mixing of the modeled water column, with a surface density field reaching $29.13-29.14$ and a maximum penetration depth of $500 \mathrm{~m}$, about twice that of the previous year's simulation (Figure 9b). The deepest mixing occurred after mid-February. In situ observation made in mid-February in SAG showed the outcropping of the isopycnal 29.15 suggesting a vertical mixing in the core of gyre up to $500 \mathrm{~m}$ [Manca et al., 2002, Figure 12]. The results of our model are in close agreement with this scenario (Figure 9). The integrated buoyancy flux (not shown) at the time of the convective event was $-0.9 \mathrm{~m}^{2} \mathrm{~s}^{-2}$, about $33 \%$ more than that of the previous year, is responsible of the greater vertical mixing.
[42] During early March, fluxes decrease to near zero and some surface restratification is present in the upper few meters. However, as a consequence of another heat loss event $\left(300 \mathrm{~W} \mathrm{~m}^{-2}\right)$ in mid-March the water column is rehomogenized again down to $500 \mathrm{~m}$. Subsequently, fluxes become predominantly positive and spring restratification progresses without interruption.

[43] Because of the greater atmospheric forcing and consequent deeper and prolonged vertical mixing, the surface layer has much more nitrate (up to $3.75 \mu \mathrm{M}$ ) during the period of deepest convection (February-March) compared to the previous year (Figure 10b). The phytoplankton increase begins mid-March and lasts about a month, using up almost all of the available nitrate. Elevated pigment concentrations $(>2.0 \mu \mathrm{M})$ occur down to over $40 \mathrm{~m}$ depth, with maximum values at the surface $(>3.0 \mu \mathrm{M})$. The rapidly 

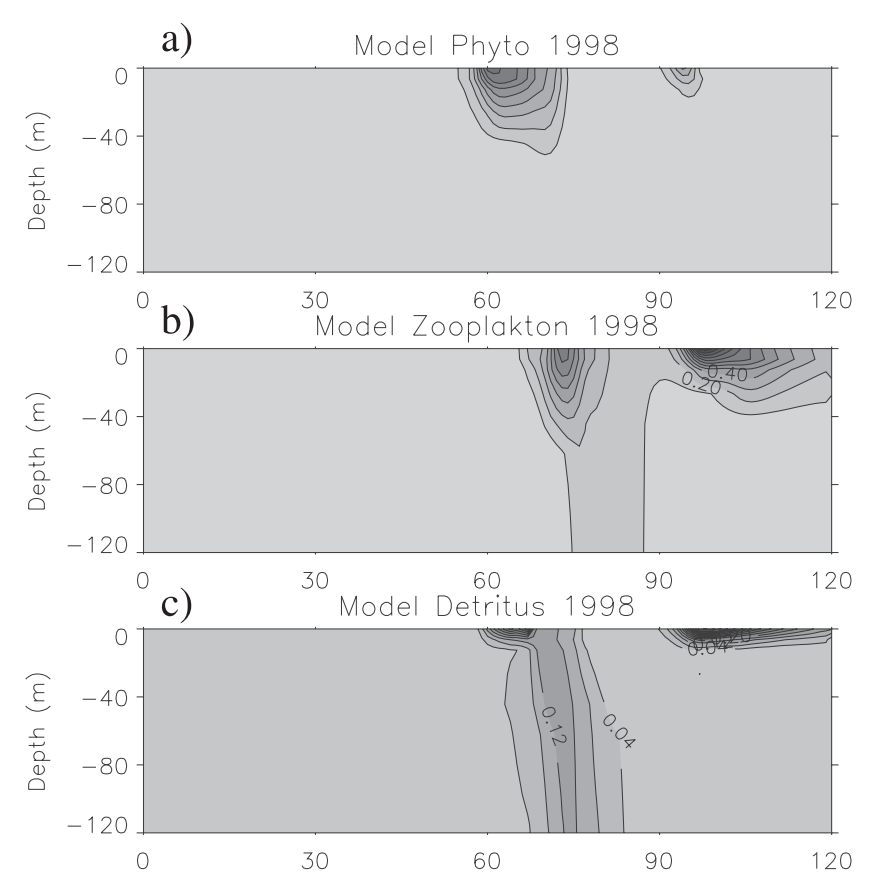

d)

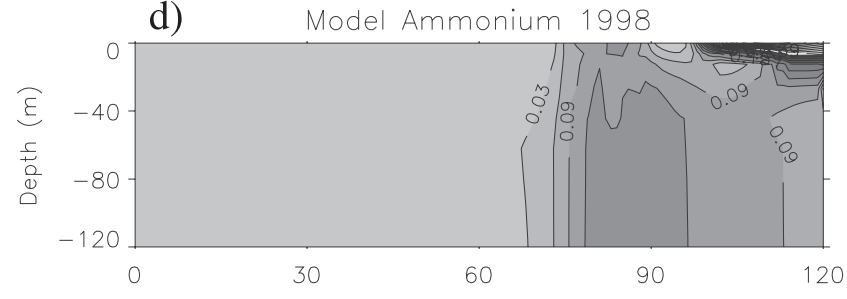

Figure 11. The 1998 simulated distribution of (a) phytoplankton, contour interval 0.25 ; (b) zooplankton, contour interval 0.1 ; (c) detritus, contour interval 0.05 ; and (d) ammounioum in the upper $120 \mathrm{~m}$, contour interval 0.03 . Units are in $\mu \mathrm{MN}$.

increasing zooplankton become abundant (maximum $>1.5 \mu \mathrm{M} \mathrm{N}$ ) within two weeks after the bloom onset, then slowly decline in April. Soon after the bloom onset, detritus begins to accumulate at the base of the phytoplankton layer, then begins to extend deeper when zooplankton are at a maximum. At about the same time, a secondary maximum occupies the first $10 \mathrm{~m}$ of the water column. An increase in ammonium in mid-April follows the zooplankton increase suggesting their importance in nutrient recycling (Figure 12).

\subsection{October 1999 to April 2000}

[44] Net heat fluxes for 2000 indicate more severe cooling compared to the previous two years (Figure 8c). In particular, over the preconditioning period (November 1999 to February 2000), the daily $\mathrm{Q}_{\text {tot }}$ averaged $-185 \mathrm{~W} \mathrm{~m}^{-2}$. The heat losses of $>200 \mathrm{~W} \mathrm{~m}^{-2} \mathrm{~d}^{-1}$ were frequent, and on at least in four occasions, exceeded $400 \mathrm{~W} \mathrm{~m}^{-2}$. The model mixed layer progression was quite similar to that of the previous year (Figure 9c). Convective penetration was deeper, extending down to $550 \mathrm{~m}$ in mid-February when the integrated buoyancy fluxes reached $-1.3 \mathrm{~m}^{2} \mathrm{~s}^{-2}$ (Figure 4). A week-long heat loss event homogenized the water column to $650 \mathrm{~m}$ around mid-March. With increasing solar altitude and lowering wind intensity, the heat fluxes became positive by the end of March, leading to reconstruction of the model thermocline. Compared to the other years, fluctuations in April between negative and positive fluxes were much greater, prompting a more variable behavior in water column restratification.

[45] An opportunity to compare our physical model results with observations was provided by an XBT transect performed every two weeks in the year 2000 in the framework of the Mediterranean Forecasting System Pilot Project (MFSPP). Figure 9(bottom) shows excellent agreement between the model and mixed layer depth derived by the XBT data http://doga.ogs.trieste.it/mfspp_ogs/index. $\mathrm{html}$ ), not only from the preconditioning to the deep convection phase when the water column mixed down to $>600 \mathrm{~m}$, but also during restratification. XBT data from the gyre center confirm the occurrence of deep convection down to $600 \mathrm{~m}$ between February 8 and 22, the persistence of vertical mixing until the end of March, and restratification of the upper layer in April. This quantitative and qualitative agreement with experimental data reaffirms that the model well reproduces the year-to-year vertical structure. Mertens and Schott [1998] underlined that such agreement between a meteorologically forced mixed layer model with observation
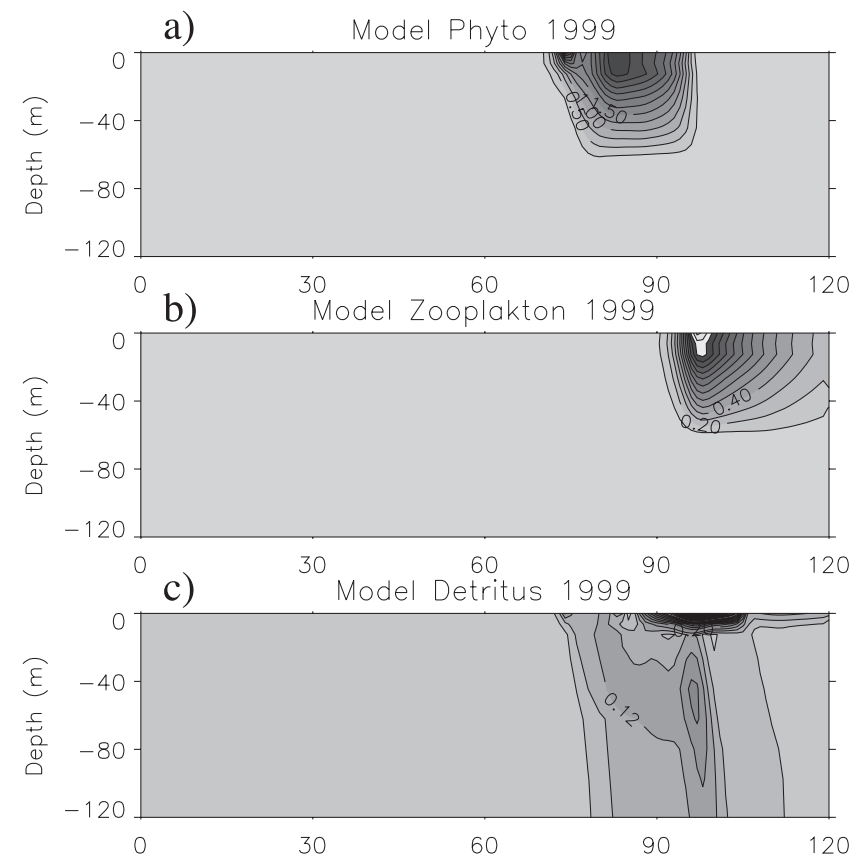

d)

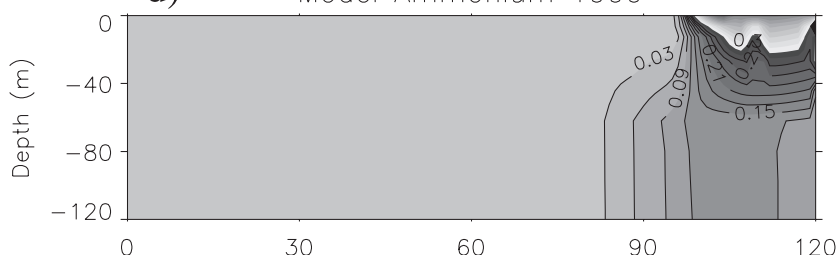

Figure 12. The 1999 simulated distribution of (a) phytoplankton, contour interval 0.25 ; (b) zooplankton, contour interval 0.1 ; (c) detritus, contour interval 0.05 ; and (d) ammounioum in the upper $120 \mathrm{~m}$, contour interval 0.03 . Units are in $\mu \mathrm{MN}$. 

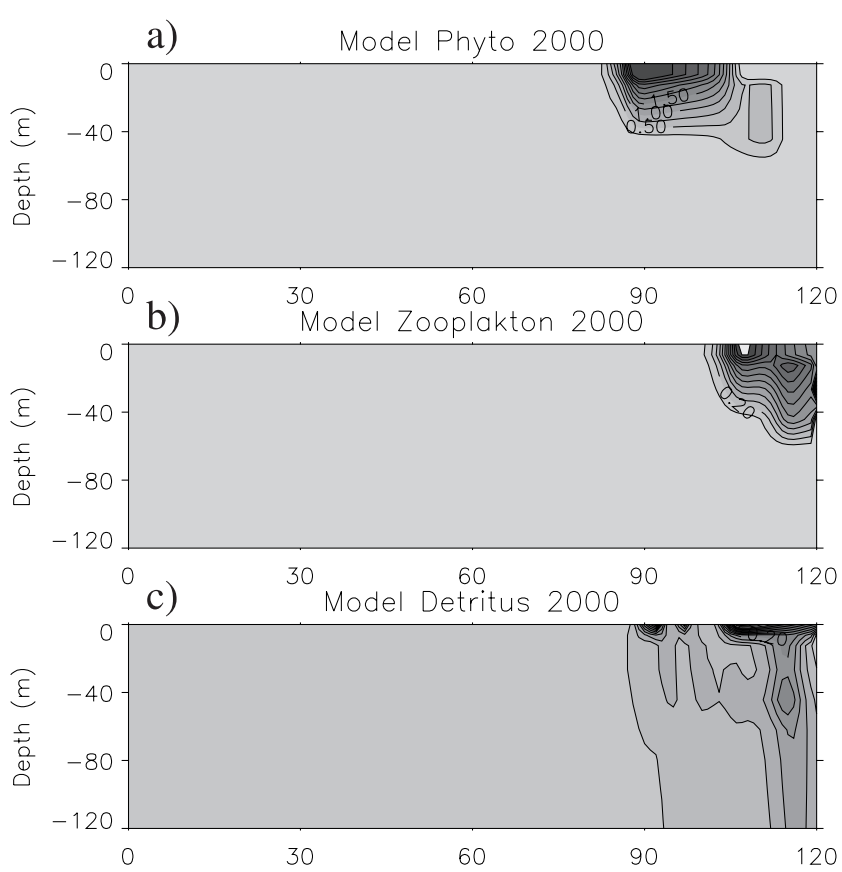

d)

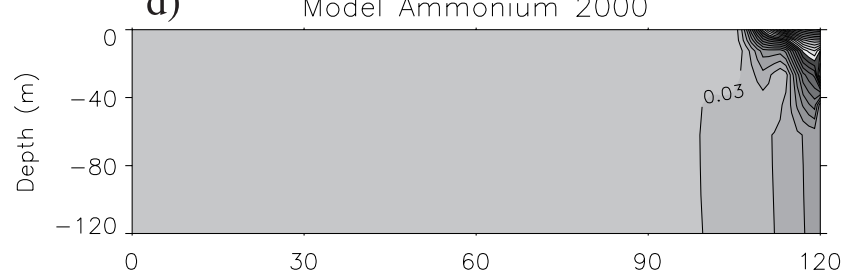

Figure 13. The 2000 simulated distribution of (a) phytoplankton, contour interval 0.25 ; (b) zooplankton, contour interval $0.1 ;$ (c) detritus, contour interval 0.05 ; and (d) ammounioum in the upper $120 \mathrm{~m}$, contour interval 0.03. Units are in $\mu \mathrm{MN}$.

essentially implies that the local heat flux plays the dominant role in driving deep convection. Our results indicate that in the SAG region, the role of air-sea fluxes is dominant and can explain most of the year to year variability of the depth and time of vertical mixing.

[46] Similar to the previous year's simulation, the deep convective penetration introduced a significant amount of nitrate in the upper layer (Figure 10c). During the entire months of February and March, surface concentrations were high, approximately $4 \mu \mathrm{M}$. Because of prolonged mixing, phytoplankton increases in April, later than the previous years. The phytoplankton bloom is confined to the first $40 \mathrm{~m}$ for the first two weeks with a surface maximum $>3 \mu \mathrm{M}$. Later, the bloom becomes weaker and develops a subsurface pigment maximum. The zooplankton behavior follows that of phytoplankton with a lag of about a week. The detritus has a similar pattern as the previous year, with accumulation initially in the vicinity of the bloom then extending deeper as zooplankton become more important, and form a secondary surface maximum. Like the other components, ammonium begins to form later than in previous years, in mid April when zooplankton increase (Figure 13).

\section{Comparison of SeaWiFS Observation and Model Results}

[47] In this section, model results are compared with SeaWiFS observations of the bloom. Unfortunately no in situ chlorophyll data are available for the examined period apart from observations made in March 1999 by Boldrin et al. [2002]. To facilitate comparisons and to better visualize the timing of bloom events, chlorophyll concentrations along a transect (shown in Figure 1) were interpolated in time and space using a weighted Gaussian function with $e$-folding of 3 days in time, and $10 \mathrm{~km}$ in space. The temporal progression of chlorophyll along the transect is compared with the model evolution of the density structure and chlorophyll profile in the surface layer (upper $60 \mathrm{~m}$ ) from January to April of each year to investigate the correspondence in timing of events (Figure 14). The model chlorophyll concentration integrated over the euphotic layer is plotted against the SeaWiFS average chlorophyll in the gyre.

[48] The transect summarizes the bloom development for the three years and clearly shows differences in timing, spatial extent and intensity. The timing of the bloom is clearly reproduced by the model, indicating the main role of meteorological forcing in determining onset and evolution of the bloom. In correspondence to decreased wind stress and the increased solar radiation over the area, the heat fluxes become positive (Figure 8) and the simulations show density restratification and increased phytoplankton biomass in the upper layer. The period of low chlorophyll observed in the SeaWiFS transect corresponds to deepening of the mixed layer up to its maximum extent (see also Figure 9). The low pigment concentrations can explained by the shorter residence time of individual phytoplankton cells in the euphotic zone, which is a consequence of the extended length of the vertical pathway of individual cells being transported by the velocity field [Wehde et al., 2001].

[49] In the chlorophyll transect of 1998 (Figure 14a), the two main bloom events described in section 3, as well as the appearance of the minimal chlorophyll "hole" in between, are easily recognized. The first well-developed bloom occurs shortly after the progressive mixed layer deepening has ceased at the end of February. In the simulation we observed a density restratification in the first $10 \mathrm{~m}$ which allowed the phytoplankton concentration to increase down to $\approx 40 \mathrm{~m}$. This model result is consistent with Townsend et al. [1992, 1994], who demonstrated that winter blooms can

Figure 14. (opposite) Time evolution of the bloom in the three years. Interpolated SeaWiFS chlorophyll concentrations along transect (shown in Figure 1) for (a) 1998, (b) 1999, and (c) 2000. Contour interval is $0.2 \mathrm{mg} \mathrm{m}^{-3}$; black region indicates no data available. Simulated density distribution within the upper $60 \mathrm{~m}$ depth for (d) 1998, (e) 1999, and (f) 2000. Simulated chlorophyll distribution within the upper $60 \mathrm{~m}$ depth for (g) 1998, (h) 1999, and (i) 2000. Comparison of SeaWiFS (thin line) and model chlorophyll (bold line) for (j) 1998, (k) 1999, and (1) 2000. The SeaWiFS Chla value time series represents the average between the two horizontal lines in the upper panels. 


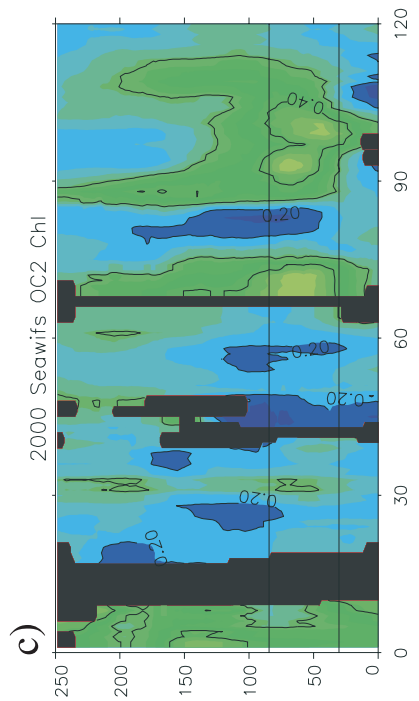

(uY) әวนDFs!0

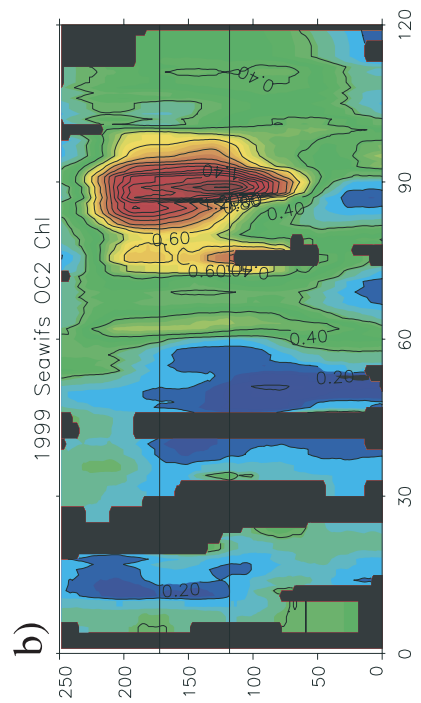

(uY) әวuDłs!0

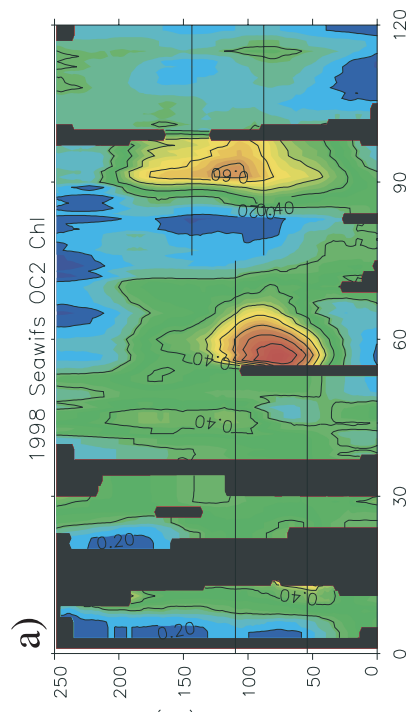

(ur) วoubłs!

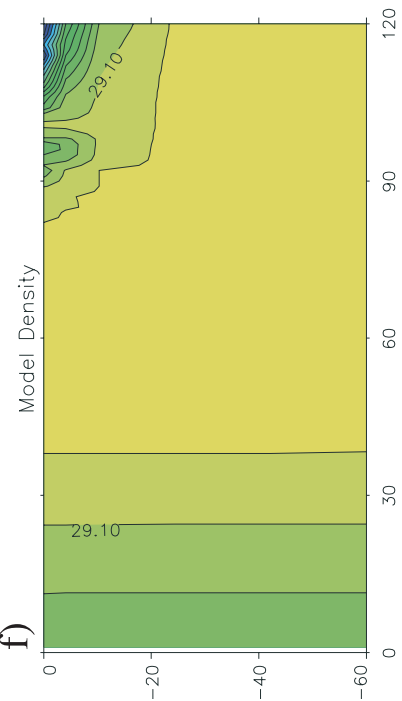

(u) $47 d ə 0$

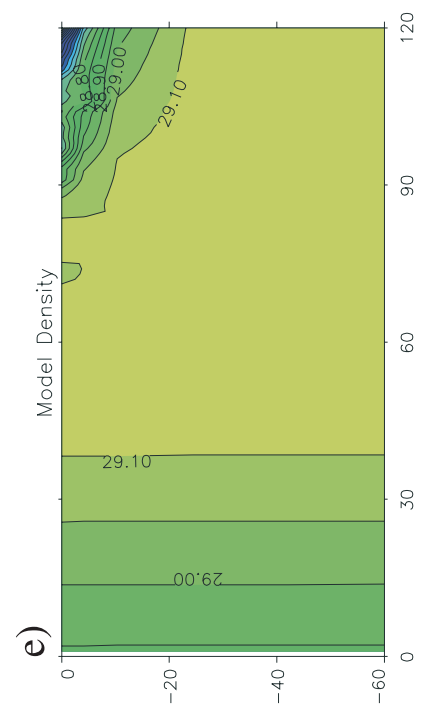

(w) $47 d ə 0$

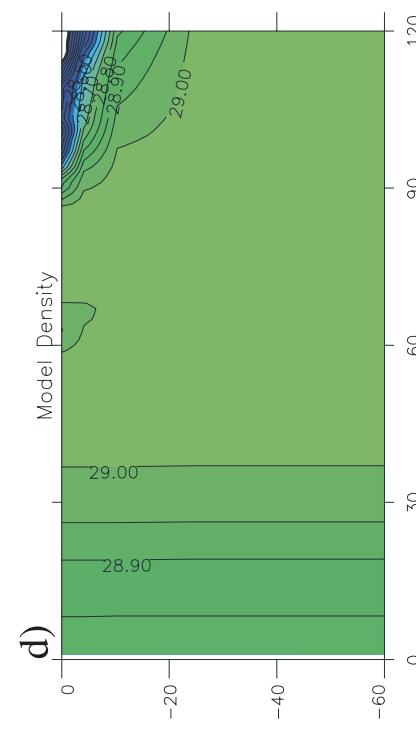

(u) पldə0

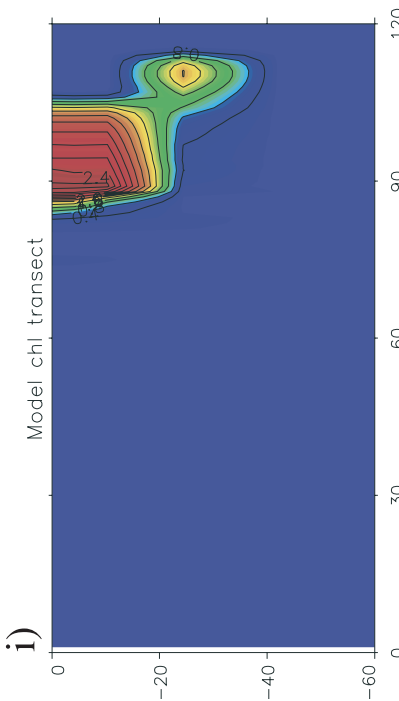

(w) $47 \mathrm{~d} ə 0$

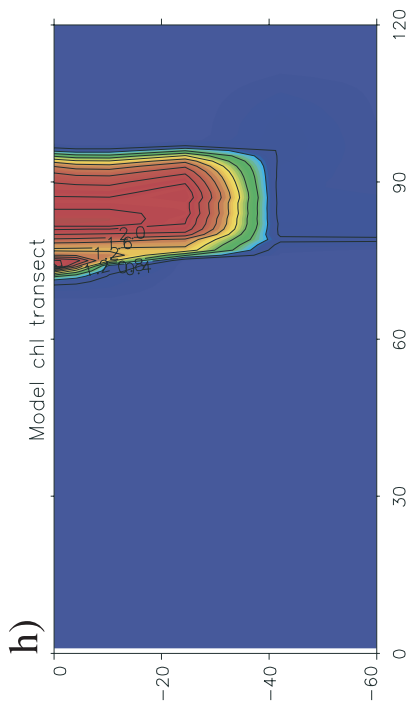

(u) $47 d ə a$

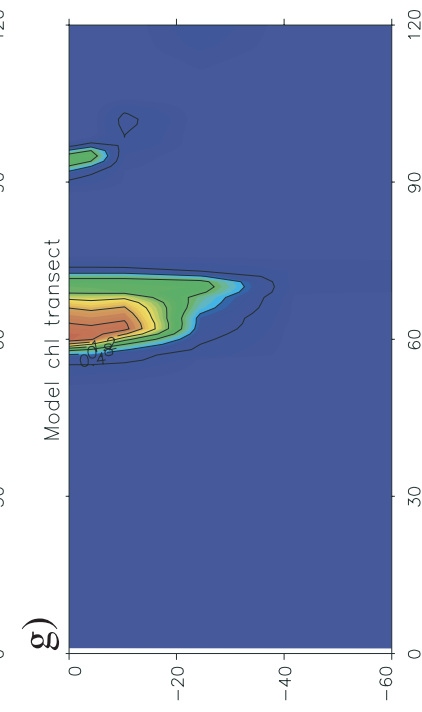

(w) $47 \mathrm{~d} ə 0$

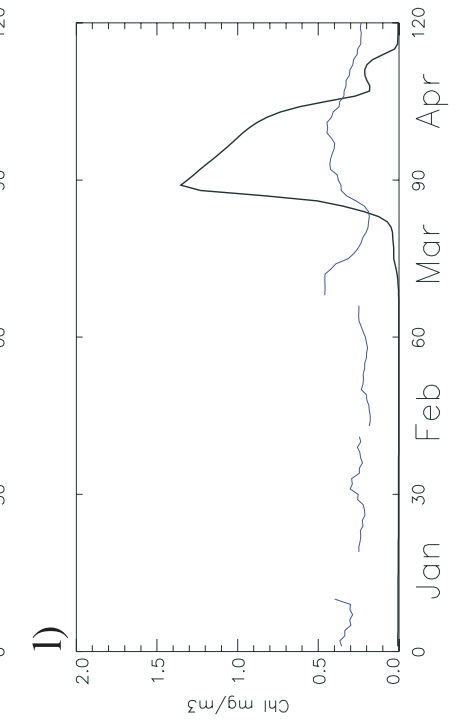

2
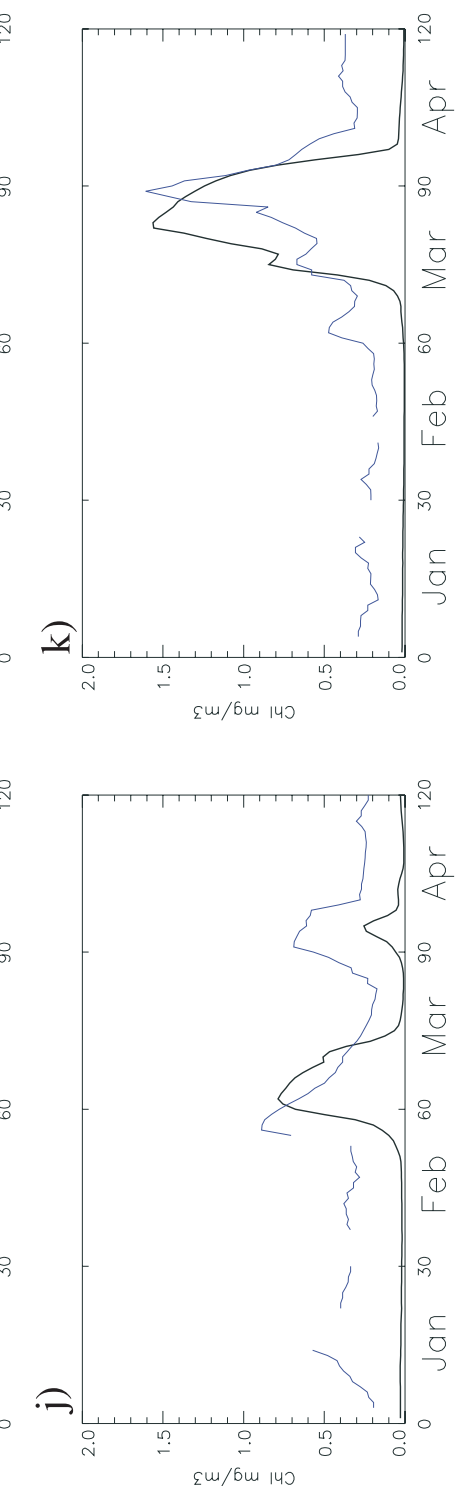
occur before the seasonal thermocline develops because of restratification in the upper few meters of the water column. In March, a series of intense wind bursts lasting for 20 days interrupts the initial bloom, and destroys the stratified layer, also leading to maximum mixing penetration (Figure 14d and Figure 9a). This minimum in chlorophyll concentration (in Figure 14a) which appears as the "hole" in the image time series (Figure 3) suggests that the minimum area in pigment concentrations correspond to the deep convective patch. The model also shows a sudden decrease of phytoplankton. By April, a net heat gain in the upper ocean (Figure 8a) permits the seasonal pycnocline to develop. With the onset of restratification, the second bloom occurs, lasting for about two weeks in the imagery. By mid-April, the bloom declines, because the upwelled nutrients have been consumed and grazing has set in (Figures 10a and 11b).

[50] The chlorophyll transect (Figure 14b) shows that 1999 is characterized by a single significant bloom event, preceded by a prolonged period of minimal chlorophyll. The period of depressed pigment concentration is associated with continuous penetrative mixing (Figure 9b). During these first two months, recurrent wind events and significant heat losses (Figures $7 \mathrm{~b}$ and $8 \mathrm{~b}$ ) contribute to the absence of restratification and injects nutrients into the euphotic zone. Chlorophyll reaches its minimum value in mid-February (Figure 14b) when the penetration depth extends to maximum of $500 \mathrm{~m}$, which is much greater than the previous year (Figure 9). Chlorophyll values moderately increase in early March and reaches a maximum $\left(>2.0 \mathrm{mg} \mathrm{m}^{-3}\right)$ after 20 March (Figure 14b). In this period the seasonal thermocline begins to be reestablished (Figure 14e) and a well defined phytoplankton increase is observed in the model (Figure 14h). The main bloom lasts for over three weeks and is more intense compared to the other years for both SeaWiFS and the model. The model shows high chlorophyll concentration up to $\sim 40 \mathrm{~m}$ with maximum values at the surface. Experimental evidence of this bloom is provided by Boldrin et al. [2002], who report a surface maximum of $1 \mathrm{mg} \mathrm{m}^{-3}$ in the center of SAG in early March. Their data show that the bloom propagates with a quasi-homogeneous distribution in the upper $40 \mathrm{~m}$ in agreement the model results.

[51] For 2000, Figure 14c shows generally low pigment conditions for most of the entire period examined, with two very moderate bloom events $\left(<0.7 \mathrm{mg} \mathrm{m}^{-3}\right)$. The first chlorophyll increase occurs around 10 March, much later than the previous two years. This bloom delay can be attributed to strong wind events and prolonged mixed layer deepening down to $600 \mathrm{~m}$ (Figures $7 \mathrm{c}$ and 9c). The brief chlorophyll increase corresponds to positive heat fluxes and low winds, but these conditions did not last long and were not sufficient to induce either stratification or a chlorophyll increase in the model (Figure 14f and 14i). In mid-March, an intense cooling event results in minimal chlorophyll values along the transect and the reappearance of the "hole" in the imagery. At end of March, seasonal stratification began as heat fluxes became positive (Figure 14f). These conditions favored the development of a bloom which was definitely less intense than that 1998 or 1999 . The wind regime in early April shows many frequent wind events of moderate intensity mainly from southeast (Figure 7c). The combination of wind and cloud cover variability contributed to the negative/positive heat flux oscillations, thereby modulating the restratification process in the model. In the simulation, the onset of the bloom corresponds to the beginning of restratification (Figures $14 \mathrm{f}$ and 14i). The highest pigments levels are at the surface and decrease to background values below $20 \mathrm{~m}$. The timing agrees with the SeaWiFS transect but the model algal biomass is much higher. After the first week of April, the SeaWiFS chlorophyll decreases below $0.4 \mathrm{mg} \mathrm{m}^{-3}$ coinciding with a destabilization of the water column not observed in previous years. When the water column restratifies, instead of a surface bloom, a deep chlorophyll maximum develops in the model (Figure 14i).

[52] The comparison between SeaWiFS and model can be summarized by Figures $14 j-141$. The base line of SeaWiFS is higher then the model by $0.2-0.3 \mathrm{mg} \mathrm{m}^{-3}$. This is not surprising since for the Mediterranean Sea, the SeaWiFS algorithms tends overestimate chlorophyll by a factor of two in very oligotrophic conditions $\left(<0.2 \mathrm{mg} \mathrm{m}^{-3}\right)$ [Bricaud et al., 2002; D'Ortenzio et al., 2002]. This implies that the background values should be halved while the peaks should remain unchanged. The model satisfactorily reproduced the timing, duration and intensity of the chlorophyll peak in 1999, and less accurately for the other years. In 1998, the first model peak is in good agreement with the data, but the second peak is much smaller and of shorter duration than observed. The year 2000 shows the least successful simulation because the large peak produced by the model was not observed in SeaWiFS. The model failed to reproduce the small blooms preceding the maximum deep mixing event. In the next section, some of these disparities between the satellite data and model results are examined in sensitivity experiments to provide an idea of what other mechanisms might need to be considered and hopefully measured in future research efforts.

\section{Model Sensitivity Experiments}

[53] SeaWiFS-derived chlorophyll images for three years (1998, 1999, and 2000) show that the southern Adriatic phytoplankton bloom occurred generally between the second half of February to the end of April but differed in timing, spatial extent and intensity. The first year, 1998 was characterized by two peaks, i.e., an early bloom onset which was interrupted in mid-March, then became reestablished. The following year, the bloom starts later but reached the highest surface chlorophyll concentrations and covered the most extensive area of the three years. The third year, 2000, also had a late bloom initiation and the chlorophyll increase was much less intense and less extensive compared to the two other years.

[54] We tested whether the observed interannual variability is controlled by local winter meteorological conditions that determine the convective mixing and the amount of available nutrients as proposed by Gacic et al. [2002] and Civitarese and Gacic [2001]. The year-to-year variability of the mixed layer deepening was investigated using the ecosystem model (section 3) forced with variable air-sea heat and momentum fluxes and PAR (section 2.2). In order to isolate the effect of atmospheric forcing, the same initial conditions were used for each year, for both physical and biological parameters (herein referred to the "control" run). 


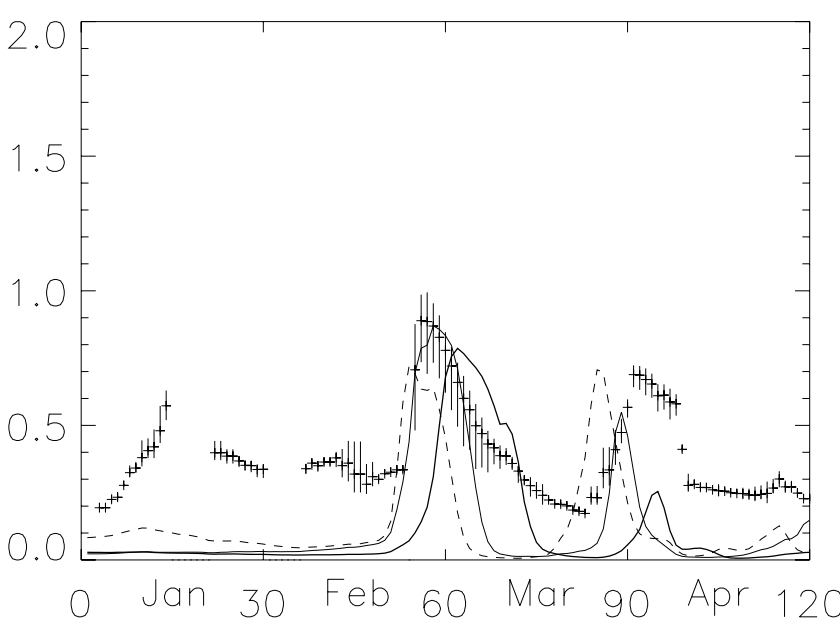

Figure 15. Results of modeling experiment for 1998 with varying phytoplankton maximum growth rate $(\sigma)$. Bold line, $\sigma=1$ (control experiment); thin line, $\sigma=1.5$; dashed line, $\sigma=2$; and crosses with vertical bars, SeaWiFS mean chlorophyll and minimum-maximum values over the region bounded by horizontal line in Figure 14a.

The results of the physical model indicate that mixed layer deepening is directly driven by intensity of the preconditioning phase during autumn and by the strong air-sea interaction events in winter. In particular, the modeled mixed layer depths extended to about $200 \mathrm{~m}$ in 1998 , $500 \mathrm{~m}$ in 1999 , and $650 \mathrm{~m}$ in 2000 , in agreement with the available in situ measurements. Thus air-sea fluxes can explain most of the year-to-year variability in depth and timing of convective mixing in the south Adriatic Gyre.

[55] The difference in observed bloom intensity between 1998 and 1999 is consistent with the hypothesis that greater mixing results in a larger bloom, but the difference between 1999 and 2000, when the mixing depths were comparable, apparently contradicts the hypothesis. The biological model successfully simulated the timing and duration of the bloom for all three years. However, the magnitude of chlorophyll concentration is reproduced well only in 1999. In 1998 the first bloom event is in agreement with the SeaWiFS observation, but the second is much smaller. In the case of 2000, the model produced a much larger peak than observed. Even though the simulated mixing depth and surface nitrate concentrations in 2000 were the highest of the three years, the bloom produced by the model is less intense compared to that 1999. All these indicate that bloom intensity does not depend solely on maximum mixing depth and its effect on nutrient availability, and that other factors such as turbulence, light limitation, grazing, may be important.

[56] First, we examine the effect of an increased maximum phytoplankton growth rate $\left(\sigma=1,1.5,2 \mathrm{~d}^{-1}\right)$ on the 1998 simulation (Figure 15). By increasing $\sigma$, we increased the magnitude of the second peak and induced an earlier initiation of the bloom. Using $\sigma=1.5 \mathrm{~d}^{-1}$, produced the most similar pattern to the satellite data which showed two peaks of comparable magnitude. In contrast, the control run produced a very small second peak. For the other two years (not shown), the $\sigma>1$ results in the unrealistic initiation of the bloom onset by over a month, indicating that this value was inappropriate. It is more instructive to view this result in the context of the delicate balance between growth and grazing, since phytoplankton biomass is the net result of both processes. A more realistic simulation of the 1998 bloom (late winter to early spring) the grazing rate $(=1.0$ in all numerical experiments) is proportionally less relative to the growth rate. Were its contribution increased, (i.e., grazing pressure exerted too soon and too intensely), there would be insufficient time for the development of strong secondary phytoplankton bloom even though nutrients are abundant. Whereas in 2000, the phytoplankton response was severely limited by vertical mixing (the "deep-mixing limitation of the bloom" of Lévy et al. [1998]), the reduced role of this physical limitation in 1998 allowed biological interactions such as grazing pressure to control phytoplankton abundance.

[57] Obviously the results of the model depend greatly on the initial nutrient budget of the water column. In the "control" simulations, all years were run with the same initial nutrient profile. In reality, Civitarese and Gacic [2001] observed nitrate concentrations (averaged from 200-800 m depth) of 5.5, 4.5, and 3.5 $\mu \mathrm{M}$ for the fall of 1997, 1998, and 1999, respectively. To explore the effect of this interannual variability of the nutrient pool on the SAG bloom, we performed sensitivity experiments using the values in Table 3 . The initial fall nutrient profiles were adjusted to reflect the decrease in nitrate content of intermediate waters. Relative to the control run, these represent unchanged initial conditions for 1998, but reduced nutrient availability for the next two years. Compared to the control results, the resulting pigment concentrations are lower by $<10 \%$ for 1999 (EXP A; Figure 16a). For the year 2000, lowering nitrate by $67 \%$ and $50 \%$ results in a decrease of the chlorophyll peak by $30 \%$ and $50 \%$ respectively. The decrease in 1999 is not very significant given the variability associated with the SeaWiFS spatial averaging, while the diminished model chlorophyll peak in 2000 approaches $0.8 \mathrm{mg} \mathrm{m}^{-3}$ closer to the observed value of $0.60 \mathrm{mg} \mathrm{m}^{-3}$ (EXP C; Figure 16b).

\section{Discussion and Conclusions}

[58] The results show that the maximum convective depth is not the only factor controlling the production in the SAG. It does determine nutrient availability in the euphotic zone, but in combination with the actual nutrient pool over the entire water column. Thus, contrary to Civitarese and Gacic [2001], who assert that the variability in the internal nutrient pool in the SAG does not determine carbon production because productivity in the basin is more controlled by

Table 3. Sensitivity Experiments to Variable Nitrate Concentration in the Intermediate Layers ${ }^{\mathrm{a}}$

\begin{tabular}{ccccc}
\hline Experiment & Year & $\begin{array}{c}\text { Average Nitrate } \\
(200-800 \mathrm{~m})\end{array}$ & $\begin{array}{c}\% \mathrm{~N} \\
\text { Reduction }\end{array}$ & $\begin{array}{c}\% \text { Chl } \\
\text { Reduction }\end{array}$ \\
\hline EXP A & $1998-1999$ & 4.6 & $15 \%$ & $7 \%$ \\
EXP B & $1999-2000$ & 3.6 & $37 \%$ & $31 \%$ \\
EXP C & $1999-2000$ & 2.7 & $50 \%$ & $39 \%$ \\
\hline
\end{tabular}

$\mathrm{a}_{0} \% \mathrm{~N}$ reduction indicates the percent of reduction of average nitrate concentration between 200 and $800 \mathrm{~m}$ with respect to the control run. \% $\mathrm{Chl}$ reduction indicates the corresponding reduction of the chlorophyll peak during the modeled bloom with respect to the control run. 
a)

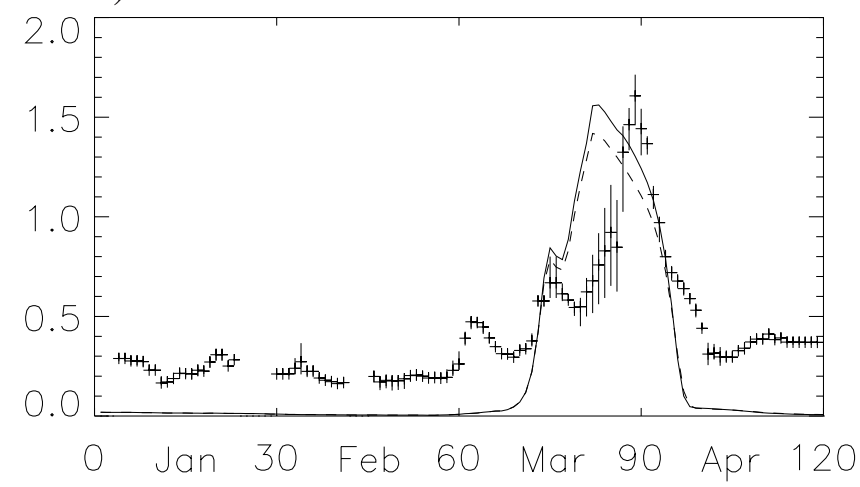

b)

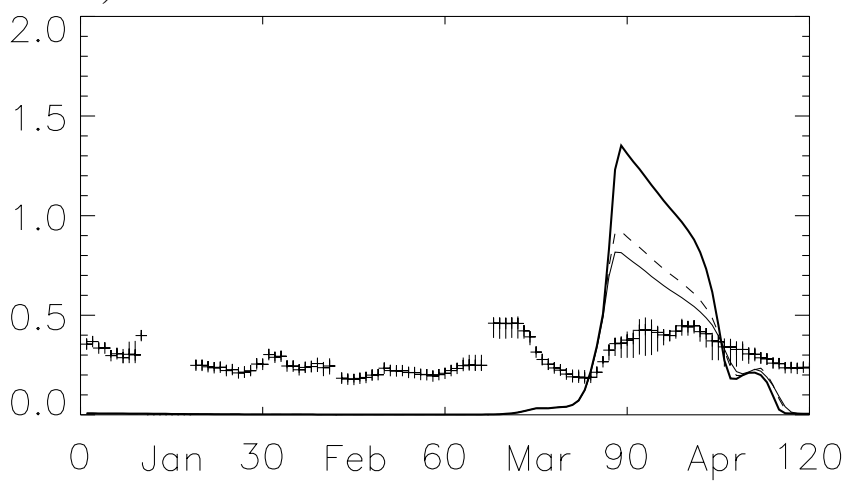

Figure 16. Results of the sensitivity experiments examining the effect of changing the initial nitrate budget (concentrations are listed in Table 3). (a) Simulation for 1998-1999 period. Bold line, control run; and dashed line, experiment A. Crosses with vertical bars represent SeaWiFS mean chlorophyll and minimum-maximum values over the region bounded by horizontal line in Figure 14b. (b) Simulation for 1999-2000 period. Bold line, control run; dashed line, experiment $\mathrm{B}$; and thin line, experiment $\mathrm{C}$. Crosses with vertical bars represents SeaWiFS mean chlorophyll and minimum-maximum values over the region bounded by horizontal line in Figure 14c.

convective mixing events, the SeaWiFs data show that for 1999 and 2000 when the convective depths are increasing, the productivity is much lower during the latter year. Our model experiments, inspired by in situ and satellite observations, indicate that the most probable explanation for the low SeaWiFS phytoplankton biomass observed in 2000 is the reduced nutrient pool because of the return from the transient phase of the Mediterranean Sea.

[59] We should also consider that the effect of atmospheric forcing on the bloom is not limited to convective penetration depths but also extends to the mixing rates. In the framework of the Sverdrup's critical depth theory, Dutkiewicz et al. [2001] proposed a simple model to examine the interannual variability in spring time chlorophyll concentration as a response to these factors. They suggested that the plankton production is a function of the mixing rates and identified regimes in which enhanced mixing can either increase or decrease bloom intensity.
The extent of these regimes was defined simply throughout the nondimensional parameter $\left(\mathrm{h}_{\mathrm{c}} / \mathrm{h}_{\mathrm{m}}\right)$ : the ratio of spring critical layer depth and winter mixed layer depth. They found that, in subtropical regime $\left(0.6<\mathrm{h}_{\mathrm{c}} / \mathrm{h}_{\mathrm{m}}<\sim 1\right)$, the vertical mixing can promote surface productivity through enhanced nutrient supply while in subpolar regime $\left(\mathrm{h}_{\mathrm{c}} / \mathrm{h}_{\mathrm{m}}<\right.$ 0.4) the vertical mixing can retard the bloom because of transport of phytoplankton below Sverdrup's critical depth.

[60] In Table 4, we show the year-to-year variability of $h_{c} /$ $\mathrm{h}_{\mathrm{m}}$ for the SAG for our study period. The $\mathrm{h}_{\mathrm{c}}$ was calculated as described by Follows and Dutkiewicz [2002] and the winter mixed layer depth and turbulent kinetic energy (TKE) was provided by our model output and published in situ observations. During our study period, all $h_{c} / h_{m}$ fall within the subpolar regime and show a steady decrease from 1998 to 2000 . The ratio for 1999 and 2000 is very similar to the climatological value while that for 1998 is distinctly greater. Thus a difference in biological response to physical forcing can be expected. Actually, the SAG exhibits a much greater variation in the critical depth ratio if other years are considered. For example, Gacic et al. [2002] report that in 1997, there was almost no winter convection, and phytoplankton production, as inferred from sediment trap data, was low. The $h_{c} / h_{m}$ ratio for this year is well within the subtropical regime. The shifting from subtropical to subpolar regimes (as defined by the $h_{c} / h_{m}$ ratio)in the SAG implies that this ecosystem's sensitivity to mixing can change dramatically. On the basis of theoretical limits, the transition between regimes occurs when mixing exceeds $\sim 76-115 \mathrm{~m}$. During the transient, generally characterized by milder winters and therefore limited capability to form dense water [Klein et al., 2000], the mixed layer is typically shallower and tends toward a subtropical regime. Thus a strong convective mixing rate leads to enhanced phytoplankton production. In contrast, during pretransient and posttransient conditions, the system falls within the subpolar regime where the mixed layer is deeper $h_{c} / h_{m} \ll 1$, the sensitivity to convective mixing is weaker, and the increase of mixing can lead to a lower phytoplankton abundance [Dutkiewicz et al., 2001]. Now that the transient has ended, the nutrient pool in the SAG should stabilize around the

Table 4. Estimate of Spring Critical Depth $\left(\mathrm{h}_{\mathrm{c}}\right)$ and Winter Mixed Layer Depth $\left(\mathrm{h}_{\mathrm{m}}\right)$ Ratio $^{\mathrm{a}}$

\begin{tabular}{|c|c|c|c|c|}
\hline Year & $\begin{array}{l}\text { Winter Mixed } \\
\text { Layer Depth, m }\end{array}$ & $\begin{array}{l}\text { Spring Critical Depth } \\
\text { (March-April) }\end{array}$ & hc/hm & $\begin{array}{c}\text { TKE } \\
\text { (March-April) }\end{array}$ \\
\hline 1998 & $200^{\mathrm{b}}$ & 41 & 0.20 & 3.7 \\
\hline 1999 & $500^{\mathrm{b}}$ & 38 & 0.08 & 3.7 \\
\hline 2000 & $650^{\mathrm{b}}$ & 43 & 0.07 & 5.5 \\
\hline 1997 & $23-35^{\mathrm{c}}$ & 45 & $1.9-1.3$ & - \\
\hline 1998 & $300^{c}$ & 41 & 0.14 & - \\
\hline Clima & $550^{\mathrm{d}}-600^{\mathrm{e}}$ & $46^{\mathrm{f}}$ & $0.084-0.077$ & - \\
\hline
\end{tabular}

${ }^{a}$ Here $h_{c}$ was computed as the depth at which vertically averaged flux of photosynthetically active radiation (PAR derived from ECMWF shortwave radiation budget) is reduced to $21 \mathrm{~W} \mathrm{~m}^{-2}$ and averaged over the bloom period [Follows and Dutckiewicz, 2002].

${ }^{\mathrm{b}}$ Mixed layer depth estimated from the mixed layer model.

${ }^{\mathrm{c}}$ Mixed layer depth from Gacic et al. [2002].

${ }^{\mathrm{d}}$ Mixed layer depth from MOM-GFDL [Artale et al., 2002].

${ }^{\mathrm{e}}$ Mixed layer depth from MED6-MODB. Model derived Turbulent Kinetic Energy (TKE) integrated both over the mixed layer and in time during the bloom period.

${ }^{\mathrm{f}}$ Critical depth derived using shorthwave radiation obtained from Southampton Ocean Centre climatology [Josey et al., 1999]. 
climatological value, i.e., $3.5 \mu \mathrm{M}$. Under this subpolar regime, a large bloom could occur only if springtime mixing rates are very low [see Follows and Dutkiewicz, 2002, Figure 2].

[61] All these considerations suggest that the intense blooms observed in 1998 and 1999 are the episodic signatures of the returning phase from EMT, when deep mixing events occurred, typical of the subpolar pre-EMT regime, and nutrient concentration at intermediate levels were still higher than climatological levels. This hypothesis was further tested by examining the whole CZCS time series from 1979 to1985. During these years only very moderate spring blooms (chlorophyll concentration between 0.3 and $0.5 \mathrm{mg} \mathrm{m}^{-3}$ ) were observed. The most intense bloom occurred in March 1982 when chlorophyll concentrations reached $0.7 \mathrm{mg} \mathrm{m}^{-3}$. This agrees with the previous analysis by Antoine et al. [1995], who found that the spring average chlorophyll in SAG is $0.3-0.4 \mathrm{mg} \mathrm{m}^{-3}$. Even if the frequency of the CZCS observations was not as high as that from SeaWiFS, the number of available scenes and the typical duration of the event strongly support the hypothesis that the 1998 and 1999 blooms were "special events" while the weaker 2000 bloom can be considered the normal south Adriatic situation. These additional analyses provide additional support to the idea that the SAG bloom is a complex phenomenon and cannot simply be explained by interannual changes in convective depth.

[62] While our numerical model results are encouraging and useful for the scope of our study, several uncertainties are present. First of all, the ECMWF atmospheric forcing could differ from the reality in many cases, with consequences on the modeled mixed layer evolution. For example, during intense evaporative events, it is known that ECMWF wind intensities are not always as strong as in situ values [Cavaleri and Bertotti, 1997], and could thereby cause an underestimate of buoyancy loss. Also, the ECMWF modeled cloud cover can differ significantly from in situ measurements, thereby affecting the shortwave and longwave radiation budget. Another consideration is the use of bulk formulae, which introduce other uncertainties in the final net budget estimate. Although freshwater input and its variability over the study period was ignored, the effect is probably small. For similar calculations in the Gulf of Lion, Mertens and Schott [1998] estimated that buoyancy fluxes would change by $2 \%$ if actual precipitation data were used.

[63] Concerning the numerical physical-biological model used, it is necessary underline the following aspects. The use of nitrates as the sole limiting nutrient in the SAG was briefly discussed in section 3. Although recent studies indicate that the SAG is strongly nitrogen-limited [e.g., Civitarese and Gacic, 2001], others suggest that both phosphorus and nitrate are important [Zavatarelli et al., 2000; Allen et al., 1998]. Our model results therefore may overestimate the primary production and phytoplankton biomass to some extent. Even though our simulations dealt specifically with the autumn to winter to early spring periods, the response of phytoplankton biomass, and consequently the primary production (not computed in this context), may be modified by several processes not included within a one-dimensional approach. In the SAG, the upward advective flux of nitrates associated with the permanent cyclonic circulation system is expected to promote stronger subsurface production during the stratification phase and the development of a seasonal thermocline. The atmospheric input and nitrogen fixation might be responsible for triggering biological activity by enhancing nitrogen concentration inside the mixed layer. Furthermore, lateral advection of flow through eddy fluxes might provide additional nitrate supply which enhances primary production. Since field observations in the SAG indicate that typical average current velocities in the gyre center are in the order of only $1 \mathrm{~cm} \mathrm{~s}^{-1}$ [Civitarese and Gacic, 2001], the horizontal contribution might be unimportant at the SAG center. Representation of phytoplankton and zooplankton by single aggregated compartments introduces strong limitation on the phytoplankton-zooplankton interaction during the year. While introducing size fractionation for these groups enhances the subsurface production during the summer and autumn seasons, this complication should not be necessary for our study since it focuses on the bloom mechanism only. Moreover, this is not yet feasible for the Mediterranean Sea and particularly, for the SAG, where there are insufficient data to represent the specific details of complicated trophic interactions.

[64] The modeling study has been useful in investigating interannual variability in the SAG, but the SeaWiFS time series also reveal intriguing 2-D aspects of the chlorophyll distributions that can be explained in the context of deep convective processes. A recurring pattern in the image time series is the appearance of a well-organized area of minimal chlorophyll concentrations sometime in the January to March period, in correspondence to a bloom delay or interruption. The low-chlorophyll area subsequently contracts as chlorophyll-rich peripheral eddies form and propagate to the center. The sequence observed in the satellite imagery is consistent with Lévy et al. [1999, 2000], who simulated bloom development during restratification following wintertime deep convection in the Gulf of Lion. These patterns are also similar to those observed in dye experiments and modeling simulations of baroclinic instability process associated with deep convection [see Marshall and Schott, 1998]. While there are no in situ chlorophyll data to validate any of these relationships, the time series demonstrates the potential usefulness of ocean color imagery for monitoring convective processes not only in the $\mathrm{SAG}$, but in other regions.

[65] Acknowledgments. This work was funded by the Italian Space Agency under contract ARS-00-21 and the MODIS project NAS5-31362. The authors would also like to thank the SeaWiFS Project (Code 970.2) and the Distributed Active Archive Center (Code 902) at the Goddard Space Flight Center, Greenbelt, MD 20771, for the production and distribution of these data, respectively. These activities are sponsored by NASA's Earth Science Enterprise.

\section{References}

Allen, J. I., J. C. Blackford, and P. J. Radford, A 1-D vertically resolved modelling study of the ecosystem dynamics of the middle and southern Adriatic Sea, J. Mar. Syst., 18, 265-286, 1998.

Antoine, D., A. Morél, and J.-M. André, Algal pigment distribution and primary production in the eastern Mediterranean as derived from Coastal Zone Color Scanner observations, J. Geophys. Res., 100, 16,19316,209, 1995.

Artale, V., D. Iudicone, R. Santoleri, V. Rupolo, S. Marullo, and F. D'Ortenzio, Role of surface fluxes in ocean general circulation mod- 
els using satellite sea surface temperature: Validation of and sensitivity to the forcing frequency of the Mediterranean thermohaline circulation, J. Geophys. Res., 107(C8), 3120, doi:10.1029/2000JC000452, 2002.

Artegiani, A., D. Bregant, E. Paschini, N. Pinardi, F. Raicich, and A. Russo, The Adriatic Sea general circulation: Part I: Air-sea interactions and water mass structure, J. Phys. Oceanogr., 27, 1492-1514, 1997a.

Backhaus, J. O., H. Wehde, E. Nost Hegseth, and J. Kämpf, 'Phyto-convection - On the role of oceanic convection in primary production, Mar. Ecol. Prog. Ser., 189, 77-92, 1999.

Banzon, P. V., E. Böhm, F. D’Ortenzio, R. Santoleri, E. D'Acunzo, and L. Lamorgese, Spatial and temporal variability in the Adriatic Sea; combined use of SeaWiFS and AVHRR data, in Remote Sensing for Earth Science, Ocean and Sea Ice Applications, edited by G. Cecchi, E. T. Engman, and E. Zilioli, Proc. SPIE Int. Soc. Opt. Eng., 3868, pp. 558-566, 1999

Barale, V., C. R. McClain, and P. Malanotte-Rizzoli, Space and time variability of the surface color field in the northern Adriatic Sea, J. Geophys. Res., 91, 12,957-12,974, 1986

Bignami, F., S. Marullo, R. Santoleri, and M. E. Schiano, Longwave radiation budget in the Mediterranean Sea, J. Geophys. Res., 100, 2501-2514, 1995.

Boldrin, A., S. Miserocchi, S. Rabitti, M. M. Turchetto, V. Balboni, and G. Socal, Particulate matter in the southern Adriatic and Ionian Sea: Characterisation and downward fluxes, J. Mar. Syst., 33-34, 389-410, 2002

Brankart, J. M., and N. Pinardi, Abrupt cooling of the Mediterranean Levantine Intermediate Water at the beginning of the 1980s: Observational evidence and model simulation, J. Phys. Oceanogr., 31, 2307-2320, 1980

Bricaud, A., E. Bosc, and D. Antoine, Algal biomass and sea surface temperature in the Mediterranean Basin: Intercomparison of data from various satellite sensors, and implication for primary production estimate, Remote Sens. Environ., 81, 163-178, 2002.

Buongiorno-Nardelli, B., and E. Salusti, On dense water formation criteria and their application to the Mediterranean Sea, Deep Sea Res., Part I, 47, $193-221,2000$.

Cavaleri, L., and L. Bertotti, In search of the correct wind and wave fields in a minor basin, Mon. Weather Rev., 125, 1964-1975, 1997.

Civitarese, G., and M. Gacic, Had the eastern Mediterranean Transient an impact on the new production in the southern Adriatic?, Geophys. Res. Lett., 28, 1627-1630, 2001.

Crise, A., G. Crispi, and E. Mauri, A seasonal three-dimensional study of the nitrogen cycle in the Mediterranean Sea: PartI. Model implementation and numerical results, J. Mar. Syst., 18, 287-312, 1998.

Crispi, G., A. Crise, and E. Mauri, A seasonal three-dimensional study of the nitrogen cycle in the Mediterranean Sea: Part II. Verification of the energy constrained trophic model, J. Mar. Syst., 20, 357-379, 1999.

D'Ortenzio, F., S. Marullo, M. Ragni, M. Ribera D'Alcalà, and R. Santoleri, Validation of empirical SeaWiFS algorithms for chlorophyll-a retrieval in the Mediterranean Sea: A case study for oligotrophic seas, Remote Sens. Environ., 82, 79-94, 2002.

Dutkiewicz, S., M. J. Follows, J. C. Marshall, and W. W. Gregg, Interannual variability of phytoplankton abundance in the North Atlantic, Deep Sea Res., Part II., 48, 2323-2344, 2001.

Follows, M. J., and S. Dutkiewicz, Meteorological modulation of the North Atlantic spring bloom, Deep Sea Res., Part II, 49, 321-344, 2002.

Gacic, M., S. Marullo, R. Santoleri, and A. Bergamasco, Analysis of the seasonal and interannual variability of the sea surface temperature field in the Adriatic Sea from AVHRR data (1984-1992), J. Geophys. Res., 102, 22,937-22,946, 1997.

Gacic, M., G. Civitarese, S. Miserocchi, V. Cardin, A. Crise, and E. Mauri, The open-ocean convection in the southern Adriatic: A controlling mechanism of the spring phytoplankton bloom, Cont. Shelf Res., 22, $1897-$ 1908, 2002.

Gill, A. E., Atmosphere-Ocean Dynamics, Int. Geophys. Ser., vol. 30, 662 pp., Academic, San Diego, Calif., 1982.

Gilman, C., and C. Garrett, Heat flux parameterizations for the Mediterranean Sea: The role of atmospheric aerosols and constraints from the water budget, J. Geophys. Res., 99, 5119-5134, 1994.

Jones, H., and J. Marshall, Restratification after deep convection, J. Phys. Oceanogr., 27, 2276-2287, 1997.

Josey, S. A., E. C. Kent, and P. K. Taylor, New insights into the ocean heat budget closure problem from analysis of the SOC air-sea flux climatologic, J. Clim., 12, 2856-2880, 1999.

Killworth, P. D., Deep convection in the world ocean, Rev. Geophys., 21, $1-26,1983$.

Kilpatrick, K., R. G. Podesta, and R. Evans, Overview of the NOAA/NASA advanced very high resolution radiometer Pathfinder algorithm for sea surface temperature and associated matchup database, J. Geophys. Res., 106, 9179-9197, 2001.
Klein, B., W. Roether, G. Civitarese, M. Gacic, B. B. Manca, and M. Ribera d'Alcalà, Is the Adriatic returning to dominate the production of Eastern Mediterranean Deep Water?, Geophys. Res. Lett., 27, $3377-$ 3380,2000

Lascaratos, A., R. G. Williams, and E. Tragou, A mixed layer study of the formation of Levantine Intermediate Water, J. Geophys. Res., 98, 14,793-14,749, 1993.

Leaman, K. D., and F. Schott, Hydrographic structure of the convection regime in the Gulf of Lions: Winter 1987, J. Phys. Oceanogr., 21, 573$596,1991$.

Lévy, M., L. Mémery, and J. M. André, Simulation of primary production and export fluxes in the northwestern Mediterranean Sea, J. Mar. Res., $56,197-238,1998$

Lévy, M., L. Mémery, and G. Madec, The onset of the spring bloom in the MEDOC area: Mesoscale spatial variability, Deep Sea Res., Part I, 46, $1137-1160,1999$

Lévy, M., L. Mémery, and G. Madec, Combined effects of mesoscale processes and atmospheric high-frequency variability on the spring bloom in the MEDOC area, Deep Sea Res., Part I, 47, 27-53, 2000.

Mallanotte-Rizzoli, P., et al., Levantine basin: A laboratory for multiple water mass formation processes, J. Geophys. Res., 108(C9), 8101, doi:10.1029/2002JC001643, in press, 2003.

Manca, B. B., V. Kovačević, M. Gacic, and D. Viezzoli, Dense water formation in the southern Adriatic Sea and spreading into the Ionian Sea in the period 1997-1999, J. Mar. Syst., 33-34, 133-154, 2002.

Maritorena, S., and J. E. O'Reilly, OC2v2: Update on the initial operational SeaWiFS chlorophyll $a$ algorithm, NASA Tech. Memo., 206892 (11), 3 8, 2000.

Marshall, J., and F. Schott, Open ocean deep convection: Observations, models, and theory, Rev. Geophys., 37, 1-64, 1999.

Marullo, S., R. Santoleri, P. Malanotte-Rizzoli, and A. Bergamasco, The sea surface temperature field in the eastern Mediterranean from advanced very high resolution radiometer (AVHRR) data part I. Seasonal variability, J. Mar. Syst., 20, 63-81, 1999

McClain, C. R., K. Arrigo, W. E. Esaias, M. Darzi, F. S. Patt., R. H. Evans, J. W. Brown, C. W. Brown, R. A. Barnes, and L. Kumar, SeaWiFS Algorithms, part 1, edited by S. B. Hooker, E. R. Firestone, and J. G. Acker, NASA Tech. Memo., 104566 (28), 45 pp., 1995.

MEDOC Group, Observation of formation of deep water in the Mediterranean Sea, Nature, 227, 1037-1040, 1970.

Mellor, G. L., User's guide for a three-dimensional, primitive equation numerical ocean model, report, 41 pp., Prog. in Atmos. and Oceanic Sci., Princeton Univ., Princeton, N.J., 1998.

Mellor, G. L., and T. Yamada, Development of a turbulent closure model for geophysical fluid problems, Rev. Geophys., 20, 851-875, 1982.

Mertens, C., and F. Schott, Interannual variability in deep-water formation in the northwestern Mediterranean, J. Phys. Oceanogr., 28, 1410-1424, 1998

Morel, A., and J.-M. André, Pigment distribution and primary production in the western Mediterranean as derived and modeled from Coastal Zone Color Scanner observations, J. Geophys. Res., 96, 12,685-12,698, 1991.

Napolitano, E., T. Oguz, P. Malanotte-Rizzoli, A. Yilmaz, and E. Sansone, Simulations of biological production in the Rhodes and Ionian Basins of the eastern Mediterranean, J. Mar. Syst., 24, 277-298, 2000.

Nival, P., G. Malara, R. Charra, and D. Boucher, La matiere organique particulaire en Mediterranee occidentale en mars 1970 (chlorophylle, proteines, glucides). Mission "Mediprod II" a du Jean-Charcot, Annal. Inst. Ocanogr., 48, 141-156, 1972.

Nival, P., S. Nival, and A. Thiriot, Infuence des conditions hivernales sur les productions phyto- et zooplanctoniques en Mediterranee nord-occidentale. V: Biomasse et production zooplanctonique-relations phyto-zooplancton, Mar. Biol., 31, 249-270, 1975.

Oguz, T., H. Ducklow, P. Malanotte-Rizzoli, S. Tugrul, N. Nezlin, and U. Unluata, Simulation of annual plankton productivity cycle in the Black Sea by a one-dimensional physical-biological model, J. Geophys. Res., $101,16,585-16,599,1996$

O’Reilly, J. E., S. Maritorena, B. G. Mitchell, D. A. Siegel, K. L. Carder, S. A. Garver, M. Kahru, and C. McClaine, Ocean color chlorophyll algorithms for SeaWiFS, J. Geophys. Res., 103, 24,937-24,953, 1998.

Pollak, M. I., The sources of the deep water in the eastern Mediterranean, J. Mar. Res., 10, 128-152, 1951.

Reed, R. K., On estimating insolation over the ocean, J. Phys. Oceanogr., 7, 482-485, 1977

Riley, G. A., The relationship of vertical turbulence and spring diatom flowerings, J. Mar. Res., 5, 67-87, 1942.

Roether, W., B. B. Manca, B. Klein, D. Bregant, D. Georgopoulos, V. Beitzel, V. Kovacevic, and A. Luchetta, Recent changes in eastern Mediterranean deep waters, Science, 271, 333-335, 1996.

Smith, S. D., Wind stress and heat flux over the ocean in gale force winds, J. Phys. Oceanogr., 10, 709-726, 1980. 
Sur, H. I., E. Ozoy, and U. Unluata, Simultaneous deep and intermediate convection in the northern Levantine Sea, winter 1992, Oceanol. Acta, 16, 33-43, 1993.

Townsend, D. W., M. D. Keller, M. E. Sieracki, and S. G. Ackleson, Spring phytoplankton blooms in the absence of vertical water column stratification, Nature, 360, 59-62, 1992.

Townsend, D. W., L. M. Cammen, P. M. Holligan, D. E. Campbell, and N. R. Pettigrew, Causes and consequences of variability in the timing of spring phytoplankton blooms, Deep Sea Res., Part I, 41, 747-765, 1994.

Visbeck, M., J. Fischer, and F. Schott, Preconditioning the Greenland Sea for deep convection: Ice formation and ice drift, J. Geophys. Res., 100, 18,489-18,501, 1995.

Wehde, H., J. O. Backhaus, and E. Nost Hegseth, The influence of oceanic convection in primary production, J. Ecol. Modelling, 138, 115-126, 2001.

Wüst, G., On the vertical circulation of the Mediterranean Sea, J. Geophys. Res., 66, 3261-3271, 1961.

Zavatarelli, M., F. Raicich, A. Artegiani, D. Bregant, and A. Russo, Climatological biogeochemical characteristics of the Adriatic Sea, J. Mar. Syst., 18, 227-263, 1998.
Zavatarelli, M., J. W. Baretta, J. G. Baretta-Bekker, and N. Pinardi, The dynamic of the Adriatic Sea ecosystem, An idealized model study, Deep Sea Res., Part I, 47, 870-937, 2000.

V. Banzon, Department of Physics, University of Miami, 4600 Rickenbacker Causeway, Miami, FL 33149-1098, USA.

F. D’Ortenzio, Stazione Zoologica A. Dohrn, Villa Comunale, 80100 Napoli, Italy.

R. Evans, Rosenstiel School of Marine and Atmospheric Sciences, University of Miami, 4600 Rickenbacker Causeway, Miami, FL 331491098, USA.

S. Marullo and E. Napolitano, Ente per le Nuove tecnologie l'Energia e l'Ambiente-Centro Ricerche Casaccia, Via Anguillarese, 301, 0060 Santa Maria di Galeria (Roma), Italy. (salvatore.marullo@casaccia.enea.it)

R. Santoleri, Istituto delle Scienze dell'Atmosfera e del Clima (Sezione di Roma), Consiglio Nazionale delle Ricerche, c/o Area della Ricerca di Roma 2-Tor Vergata, Via del Fosso del Cavaliere, 100, 00133 Roma, Italy. 